\title{
Which Firms Follow the Market? An Analysis of Corporate Investment Decisions
}

\author{
Tor-Erik Bakke \\ University of Wisconsin, Madison \\ Toni M. Whited \\ University of Wisconsin, Madison
}

Address correspondence to: Toni M. Whited, Wisconsin School of Business, 975 University Avenue, Madison, WI 53706. 608-262-6508. twhited@bus.wisc.edu. 


\title{
Which Firms Follow the Market? An Analysis of Corporate Investment Decisions
}

\begin{abstract}
We test whether stock-market mispricing or private investor information in stock prices affects corporate investment. We develop an econometric methodology that disentangles stock-price movements that are relevant for investment from those that are not. We combine this decomposition with proxies for private information and mispricing to devise unbiased tests for the effects of mispricing and information on investment. We depart from much of the literature by finding that stock-market mispricing does not affect investment, especially that of large firms and firms subject to mispricing. In contrast, we confirm previous evidence that managers incorporate private investor information when making investment decisions.
\end{abstract}

Keywords: Investment; Stock market; Signal extraction; Errors-in-variables; GMM 
How does a firm's stock price affect its investment decisions? In a perfect world of symmetric information, efficient capital markets, and no regulatory distortions, this question is uninteresting because movements in asset prices reflect changes in underlying economic fundamentals, and the fundamental value of investment is the market value. However, the question has been of interest at least since Keynes' (1936) idea that "animal spirits" influence the real economy, precisely because many accept the notion that capital markets are not entirely efficient; that is, that information does not flow freely among investors and firms. The question is also relevant for monetary policy because a link between stock prices and real economic activity opens the door for policy makers to target the stock market. The question is challenging because even an inefficient stock market passively reflects at least some of a firm manager's knowledge about genuine investment opportunities. Therefore, to answer the question one needs to disentangle such managerial knowledge from other sources of stock-price variation, such as private investor information or mispricing. Complicating any such disentanglement is the possibility of feedback from mispricing or from private information embedded in the stock price to the manager's perception of investment opportunities.

No single answer to the question has emerged. The numerous papers that tackle this question find conflicting results, and the historical evidence has been similarly mixed. Figure 1 depicts aggregate investment and the S\&P 500 index over the last 25 years. The graph reveals episodes of a strong association between the stock market and investment, such as during the recovery from the recession of 2001. The plot also shows episodes in which investment has moved independently of the stock market, such as during the 1987 stock market crash, which had no effect on real investment. Similarly, the often cited increase in investment during the stock-market bubble of the late 1990s is small in comparison to the movement in the market.

Given this background of scattered anecdotal and formal evidence, this paper takes a step back, identifies the difficulties to overcome in ascertaining whether a firm's stock price affects its investment, and then develops and applies a new econometric methodology that can tackle these difficulties. We examine two related questions: whether investment responds to mispricing or to private information embedded in the stock price. Our innovations take into account important conceptual issues previously ignored by much of the literature. Accordingly, our new approach disputes many previous empirical findings concerning the importance of mispricing for firm investment. However, we confirm previous evidence that private investor information does affect investment. 
Explaining our empirical approach requires an elaboration of the basic question. On one hand, managers may be better informed about the investment opportunities of their firms than are outside investors. In this case market signals provide no new knowledge to managers, who can, therefore, safely ignore stock market movements. In addition, managers may be reluctant to issue equity to exploit overvaluation of their company's shares because equity issuance can be a negative signal that, in the spirit of Myers and Majluf (1984), can deflate equity values.

We consider two related alternatives to this point of view. First, in Dow and Gorton (1997) and Subrahmanyam and Titman (1999) managers can improve their investment decisions by observing stock-price movements because stock prices contain information that is aggregated from investors who do not communicate directly with firms. Second, managers can respond to market mispricing of their stock when they make investment decisions. These two ideas are interconnected because mispricing provides incentives for information production, which, in turn, reduces mispricing. The second idea originates from Bosworth (1975) and Merton and Fischer (1984), who argue that if a company's stock is overvalued, managers can benefit existing shareholders by issuing equity. However, what managers do with the proceeds is an open question, and they will invest only if they have outstanding positive NPV projects - a situation likely to arise only if the firm cannot get the necessary financing. A more recent theoretical justification for a link between mispricing and investment is in Panageas (2005a). In his model investors have heterogeneous beliefs, and short sales are restricted. These two phenomena cause the shadow value of capital (marginal $q$ ) to contain a speculative bubble. Classical $q$-theory implies that investment depends on marginal $q$ and therefore, passively, on this speculative bubble.

This discussion of the mechanisms whereby stock prices affect investment is couched in terms of unobservable quantities such as mispricing and information. Any empirical examination of these issues, therefore, must deal convincingly with biases that inevitably arise in empirical studies that contain unobservables. Our methodology does. It uses a model in which investment is determined primarily, though not solely, by Tobin's $q$ : the market value of the capital stock divided by its replacement value. Because most of the variation in Tobin's $q$ stems from variation in equity, this model is ideal for investigating the effect of the stock market on investment. To isolate the effects of private information and mispricing on investment, we turn to the errors-in-variables remedy in Erickson and Whited (2000, 2002), which is applicable inasmuch as movements in the market that 
the manager considers unimportant for investment can be modeled econometrically as measurement error. This interpretation of measurement error is broader than the usual concept that considers literal errors in the recording of data. It is also closely related to the definition put forth in Erickson and Whited (2000) as any discrepancy between an observed measure of Tobin's $q$ and the manager's expectation of capital productivity. We extend this definition in a sensible direction by allowing managerial expectations to depend on movements in the stock price.

Our technique allows decomposition of the variance of Tobin's $q$ into a component the manager considers relevant for investment and a component the manager considers irrelevant. We use this decomposition to conduct two types of tests. First, if private investor information is reflected in the stock price and if the manager pays attention to this information, the relevant component should be larger. We therefore test whether groups of firms sorted by measures of private information have higher relevant components.

Second, to ascertain whether these components depend on mispricing, we regress Tobin's $q$ on proxies for mispricing and collect the residual, thereby removing variation from Tobin's $q$. We then test whether this variation has been removed from the part of Tobin's $q$ that is relevant for investment or the part that is irrelevant for investment. To distinguish these two alternatives, our tests compare the sizes of the relevant and irrelevant components before and after we regress Tobin's $q$ on the mispricing proxies. We structure our tests so that noise in our proxies does not affect test consistency. Finally, we use our technique to identify characteristics of firms that exploit stock-market mispricing, focusing on access to external finance and the level of mispricing. Because our technique is new, and because a skeptic may also find our econometric model and some of our assumptions questionable, we demonstrate the accuracy of our tests in finite samples in Monte Carlo experiments, and we go to great lengths to check the robustness of our results.

To put this method in perspective, we examine the rest of the literature, which can be divided into two strands, the first of which examines the effects of mispricing on investment. In support of this idea, Panageas (2005b) shows that investment closely followed Tobin's $q$ during a natural experiment with short-sales constraints during the 1920s. Baker, Stein, and Wurgler (2003) find a high sensitivity of investment to Tobin's $q$ for financially constrained firms, concluding that stock market mispricing leads these firms to issue equity and to use the proceeds for investment. Goyal and Yamada (2004), Chirinko and Schaller (2005), and Campello and Graham (2007) also find an 
independent role for the stock market, conditional on their proxies for fundamentals. Other papers in this strand include Gilchrist, Himmelberg, and Huberman (2005) and Polk and Sapienza (2007), both of which include proxies for mispricing in an investment- $q$ regression. Contradicting the idea that mispricing matters, Morck, Shleifer, and Vishny (1990) find that although returns can predict investment, this predictive power disappears once they control for fundamentals. Similarly, Blanchard, Rhee, and Summers (1993) find that the stock market does not affect investment, conditional on fundamentals, even though it changes the composition of external finance. Finally, Chirinko and Schaller $(1996,2001)$ use an investment Euler equation approach to find an independent role for the stock market in Japanese data, but not in U.S. data.

The second strand examines whether external information in the stock price affects investment. Chen, Goldstein, and Jiang (2007) examine the connection between the sensitivity of investment to Tobin's $q$ and measures of external information embedded in the stock price. They find a positive relation, which they interpret as evidence that managers glean information from stock prices when they make investment decisions. Using a different approach, Luo (2005) finds that merger announcement returns predict deal completions, even after controlling for deal quality, thereby concluding that merging firms extract information from stock prices.

Our paper brings many of these results together by isolating specific mechanisms through which the stock market influences investment. We do find limited evidence that firms invest after issuing overpriced equity in order to relieve a binding finance constraint. However, we find much stronger evidence that many other groups of firms ignore mispricing. Finally, we find that the portion of the variation in Tobin's $q$ that is relevant for investment rises with the amount of private investor information in the stock price.

Why do our results depart from those in the literature? The difference stems in part from more accurate identification of firms that face financial constraints. A more important difference, however, arises from the improved ability of our technique to produce unbiased tests. Many of the papers surveyed above include proxies for mispricing, information, and fundamentals in regressions of investment on Tobin's $q$. Because Tobin's $q$ is itself only a proxy for investment opportunities, such regressions contain more than one proxy. As such, the coefficients on any other proxies are therefore also biased, but, as explained in Klepper and Leamer (1984), not necessarily toward zero. In contrast, the Appendix shows that our use of proxies for mispricing does not bias our 
tests and only lowers their power. Because we find significant results, the low power is of little concern. Finally, our conclusions depart from much of the literature because our method improves upon the ambiguity inherent in one of the main empirical workhorses in this area-examination of investment- $q$ sensitivity. Several observationally equivalent forces can raise this sensitivity. One is managerial attention to mispricing or to private investor information embedded in the price. However, everything else held constant, investment- $q$ sensitivity can also be high in the absence of mispricing or private information if the price fully reflects investment opportunities. Finally, both physical and financial frictions affect investment- $q$ sensitivity. Given these difficulties, one goal in this paper is to determine in which instances previous approaches have been misleading.

The paper is organized as follows. Section 1 presents our econometric model and testing strategy. Section 2 summarizes the data, Section 3 presents the results, and Section 4 concludes. The Appendix describes the estimators a Monte Carlo experiment that evaluates their performance.

\section{Methodology}

This section describes our methodology. First, we outline our econometric model and describe our tests. Because our methods are somewhat unusual, we demonstrate in several ways that the results produced by these methods are credible. In this section we address this issue on an intuitive level by discussing the applicability of the underlying empirical model. In later sections we take a more quantitative approach by performing specification tests, conducting robustness checks, and running Monte Carlo experiments designed to assess possible finite-sample bias in our tests.

\subsection{Econometric Model}

Our testing strategy starts with the estimators in Erickson and Whited (2000, 2002). We pick this technique for three reasons. First, as explained in Erickson and Whited (2000), other, more traditional errors-in-variables remedies require implausible assumptions such as serially uncorrelated measurement errors. Second, Erickson and Whited (2000) demonstrate that this technique has good finite-sample properties in the case of cross-sectional investment regressions. Most importantly, the technique provides an estimate of the ratio of signal to the sum of signal and noise for Tobin's $q \cdot{ }^{1}$

These estimators employ the structure of the classical errors-in-variables model. Applied to a 
single cross section, this model can be written as

$$
\begin{gathered}
y_{i}=z_{i} \alpha+\chi_{i} \beta+u_{i}, \\
x_{i}=\gamma+\chi_{i}+\varepsilon_{i},
\end{gathered}
$$

in which $y_{i}$ is the ratio of investment to assets for firm $i, \chi_{i}$ is the true incentive to invest (true $q$ ), $x_{i}$ is an estimate of its true $q$, and $z_{i}$ is a row vector of perfectly measured regressors, whose first entry is one. The regression error, $u_{i}$, and the measurement error, $\varepsilon_{i}$, are assumed to be independent of each other and of $\left(z_{i}, \chi_{i}\right)$, and the observations within a cross section are assumed i.i.d. The intercept in (2) allows for bias in the measurement of true $q$.

Using the third and higher order moments of $\left(x_{i}, y_{i}\right)$, the Erickson and Whited estimators provide consistent estimates of the slope coefficients, $\alpha$ and $\beta$, as well as of the variances of the unobservable variables $\left(\chi_{i}, u_{i}, \varepsilon_{i}\right)$. These estimators are identified only if $\beta \neq 0$ and $\chi_{i}$ is nonnormally distributed. Erickson and Whited (2002) develop a test of the null hypothesis that $\beta=0$ and $\chi_{i}$ is normally distributed - a test we refer to hereafter as an identification test.

To explain the intuition behind these estimators, we consider a simple example based only on third-order moments, in which $\gamma$ and $\alpha$ have been set to zero. This estimator has a familiar instrumental variables representation, which we demonstrate as follows. First, substitute (2) into (1), and set $\gamma=\alpha=0$ to obtain

$$
y_{i}=x_{i} \beta+\left(u_{i}-\beta \varepsilon_{i}\right)
$$

This regression clearly suffers from a correlated error and regressor. However, the product of $x_{i}$ and $y_{i}$ can serve as a valid instrument for $x_{i}$ because the independence of $u_{i}, \varepsilon_{i}$, and $\chi_{i}$ implies that this instrument is orthogonal to the composite error $\left(u_{i}-\beta \varepsilon_{i}\right)$; that is, $E\left(x_{i} y_{i} u_{i}\right)=E\left(x_{i} y_{i} \varepsilon_{i}\right)=0$. Premultiplying both sides of (3) by $y_{i} x_{i}$, taking expectations, and rearranging produces

$$
\beta=\frac{E\left(y_{i}^{2} x_{i}\right)}{E\left(y_{i} x_{i}^{2}\right)} .
$$

The moments $E\left(y_{i} x_{i}^{2}\right)$ and $E\left(y_{i}^{2} x_{i}\right)$ in (4) are both third-order moments of the joint distribution of $y_{i}$ and $x_{i}$. The Erickson and Whited estimators build off of this simple third-order moment estimator by combining information in many higher order moments via GMM.

This technique produces an estimate of our parameter of interest, which is the population $R^{2}$ of 
equation (2), and which we denote $\tau^{2}$. Under our assumptions it can be written as

$$
\tau^{2}=\frac{\operatorname{var}\left(\chi_{i}\right)}{\operatorname{var}\left(x_{i}\right)}=\frac{\operatorname{var}\left(\chi_{i}\right)}{\operatorname{var}\left(\chi_{i}\right)+\operatorname{var}\left(\varepsilon_{i}\right)}
$$

From a purely econometric point of view, a value of $\tau^{2}$ close to one implies that the proxy is quite informative about variation in $\chi_{i}$. Conversely, a value close to zero implies that the proxy is nearly worthless. We discuss the economic interpretation of $\tau^{2}$ below.

Because these estimators can be applied only to samples that are arguably i.i.d., we obtain our estimates in two steps. First, we estimate $\tau^{2}$ for each cross section of our unbalanced panel. Second, we pool these estimates via the procedure in Fama and MacBeth (1973). We do not include firm fixed effects in our regressions for two reasons. First, the resulting model almost never passes the identification test. Second, when we estimate (3) via OLS both with and without fixed effects, we find almost identical results, suggesting that the within-firm variation in investment and Tobin's $q$ mirrors the cross-sectional variation. ${ }^{2}$ This result makes sense inasmuch as investment is a flow variable and therefore has already been first-differenced to remove any potential fixed effects.

Recently, Petersen (2005) has reemphasized that Fama-Macbeth standard errors can be inappropriate in panel data. Further, because we put no restrictions on the time series properties of $\left(\chi_{i}, u_{i}, \varepsilon_{i}\right),{ }^{3}$ we open the door for the nominal critical values for the t-statistics produced by these standard errors to be different from the finite-sample critical values. We therefore use the bootstrap in Hall and Horowitz (1996) to calculate the finite-sample distribution of these t-statistics. The unit of observation for resampling is the firm. Interestingly, we find that many of these finite-sample critical values are close to their asymptotic critical values, although in several instances we do find finite-sample critical values for a nominal $5 \%$ two-sided t-test as high as 4 , especially in the case of the GMM estimates of the coefficient on $\chi_{i}$.

\subsection{Test Description}

Before describing our tests we need to interpret $\tau^{2}$ in economic rather than econometric terms. To begin we note that equations (1) and (2) define $\chi_{i}$ as the part of Tobin's $q\left(x_{i}\right)$ that matters for investment and $\varepsilon_{i}$ as the part that does not. Variation in $\chi_{i}$ stems from several sources: public information about investment opportunities that is reflected in the stock price, private managerial information about investment opportunities not reflected in the stock price, managerial information 
about investment opportunities gleaned from observing the stock price, and movements in the stock price unrelated to investment opportunities. This last component could matter for investment if overpricing relieves a binding finance constraint. Variation in $\varepsilon_{i}$ is sufficiently complex to be the subject of the following subsection, in which we argue that the component of greatest interest is any deviation between the stock price and managerial perceptions of investment opportunities.

Our tests combine the two most common methods for dealing with unobservables in empirical work: the use of proxies and the imposition of structure on the econometric model. We have already described our structure. The types of tests we perform depend crucially on the types of measures of information or mispricing that are available. First we consider tests about the effects on investment of information in the stock price. In this case we can obtain measures of how much information is in the stock price (price informativeness) and not of the actual information in the price. Our test is based on the observation that if the amount of private information embedded in the stock price is high, and if this information is relevant for investment, then $\tau^{2}$ should, everything else held constant, be high. The appropriate test is then to see how $\tau^{2}$ changes across different subsamples with different degrees of informativeness.

To test the hypothesis about mispricing, we can obtain measures of the level of overpricing. This type of measure can be used differently because of the direct positive relation between overpricing and Tobin's $q$. Figure 2 provides a heuristic explanation for how we use mispricing proxies along with $\tau^{2}$ to examine whether mispricing matters for investment. Panel A depicts a typical decomposition of the variance of an observed measure of Tobin's $q$, that is, $\operatorname{var}\left(x_{i}\right)$. In the diagram this variance is represented by the distance between points $a$ and $c$. The Erickson and Whited estimators separate $\operatorname{var}\left(x_{i}\right)$ into two parts, which are represented by the distances from $a$ to $b$ and from $b$ to $c$. The distance from $a$ to $b$ represents $\operatorname{var}\left(\chi_{i}\right)$, and the distance between points $b$ and $c$ represents $\operatorname{var}\left(\varepsilon_{i}\right)$. An estimate of $\tau^{2}$ measures the ratio of the distance between points $a$ and $b$ to the distance between points $a$ and $c$. However, although estimating $\tau^{2}$ can separate these components, this estimation cannot by itself provide information on whether either component contains any mispricing.

To complete our identification strategy, we combine estimation of $\tau^{2}$ with a more common method for econometrically estimating the effects of unobservables: the use of proxies, in particular, proxies for market mispricing. Use of proxies typically results in biased regression coefficients and misleading tests. However, we structure our tests in such a way that the use of possibly noisy proxies 
does not produce bias and only lowers the power of our tests. Specifically, we perform a first-stage regression of Tobin's $q$ on each of these proxies and then make the observation that the variation thus removed has to be either relevant for investment (i.e., lie in the interval $a$ to $b$ ) or irrelevant for investment (i.e., lie in the interval $b$ to $c$ ).

Consider first the former case, in which market mispricing is relevant for managerial investment decisions, and which is depicted in Panel B of Figure 2. Because regressing Tobin's $q$ on a mispricing proxy removes information from Tobin's $q$ that is useful for investment decisions, the distance between $a$ and $b$ shrinks. We detect this effect by using the residuals from the first-stage regression ( $q$ residuals, hereafter) as $x_{i}$ in (1) and (2), and then by comparing the estimates of $\tau^{2}$ from using Tobin's $q$ in (1) and (2) with those from using the $q$ residual. Because the $q$ residual is less relevant for investment than Tobin's $q$, the estimate of $\tau^{2}$ produced by the $q$ residual is smaller. Conversely, in the second case in which the manager does not pay attention to mispricing, regressing Tobin's $q$ on a mispricing proxy removes inconsequential information from Tobin's $q$. This situation is depicted in Panel C. The distance between $b$ and $c$ shrinks, and the $q$ residual produces a higher estimate of $\tau^{2}$ than Tobin's $q$. Let $\tau_{m}^{2}$ denote the estimate of $\tau^{2}$ corresponding to the $q$ residual. We can test whether mispricing matters by testing for a significant difference between $\tau^{2}$ and $\tau_{m}^{2}$.

To describe the testing strategy more formally, let $\omega_{i}$ be a proxy for mispricing, and let $\hat{\delta} \omega_{i}$ be the fitted value from regressing $x_{i}$ on $\omega_{i}$. Next, rewrite (2) as

$$
\begin{aligned}
x_{i}-\hat{\delta} \omega_{i} & =\chi_{i}^{*}+v_{i} \\
x_{i} & =\chi_{i}^{*}+\hat{\delta} \omega_{i}+v_{i},
\end{aligned}
$$

in which $\chi_{i}^{*}$ and $v_{i}$ are defined in terms of the null and alternative hypotheses below. In this framework, the null hypothesis that $\omega_{i}$ has no effect on Tobin's $q, x_{i}$, can be written as $H_{0}: \hat{\delta}=0$. With reference to the original measurement equation, (2), if $\hat{\delta}=0$, then $\chi_{i}^{*}=\chi_{i}$ and $v_{i}=\varepsilon_{i}$; and, therefore, $\tau_{m}^{2}=\tau^{2}$. The first alternative joint hypothesis is that $\omega_{i}$ affects $x_{i}$ and that the manager pays attention to $\omega_{i}$. This hypothesis can be written as $H_{1}: \hat{\delta} \neq 0, \chi_{i}=\chi_{i}^{*}+\hat{\delta} \omega_{i}$, and $\varepsilon_{i}=v_{i}$. Under this first alternative $\tau_{m}^{2}<\tau^{2}$. The second alternative joint hypothesis that $\omega_{i}$ affects $x_{i}$ and that the manager ignores $\omega_{i}$ can be written as $H_{2}: \hat{\delta} \neq 0, \chi_{i}=\chi_{i}^{*}$, and $\varepsilon_{i}=v_{i}+\hat{\delta} \omega_{i}$. Under this second alternative $\tau_{m}^{2}>\tau^{2}$.

To examine the significance of $\tau_{m}^{2}$, we first estimate (1) and (2) using $x_{i}$. We then reestimate (1) 
and (2) using $x_{i}-\hat{\delta} \omega_{i}$ in place of $x_{i}$, thus producing estimates of $\tau_{m}^{2}$. We then form the difference $\tau_{m}^{2}-\tau^{2}$ and test whether this difference is significantly greater or less than zero. In this framework, our null hypothesis is $\tau_{m}^{2}-\tau^{2}=0$. Our first alternative hypothesis that firms react to mispricing can be expressed as $\tau_{m}^{2}-\tau^{2}<0$. Our second alternative hypothesis that firms ignore mispricing can be expressed as $\tau_{m}^{2}-\tau^{2}>0$.

We next discuss intermediate cases in which we cannot reject our null hypothesis. An obvious scenario that leads to a failure to reject is the absence of mispricing. However, our data analysis reveals that $\hat{\delta}=0$ for only one of the subsamples of firms we investigate. Because $\omega_{i}$ is a proxy, its slope coefficient is biased toward zero. Therefore, our findings of nonzero slopes make this scenario unlikely. A second reason for a failure to reject is managerial attention to a portion of mispricing combined with managerial inattention to the rest. We deal with this possibility in the robustness section below. A final scenario that can lead to a failure to reject the null is noise in our imperfect proxies for mispricing. As shown in a Monte Carlo simulation in the Appendix, however, the presence of measurement error in these proxies only lowers the power of our tests relative to a situation in which we use (hypothetical) perfect measures. It does not bias the tests. These Monte Carlo experiments also show that even the diminished power of our tests is still quite effective in detecting the alternative hypotheses that $\tau_{m}^{2}-\tau^{2}$ is either greater than or less than zero.

Three features of our testing strategy are important. First, we can quantify the extent to which the market influences investment, which is a calculation that cannot be made using previously formulated approaches. In particular, we can calculate an upper bound on the percent of the variation in $\chi_{i}$ that is due to $\omega_{i}$ if $\tau_{m}^{2}-\tau^{2}<0$. To obtain this bound, we substitute (5) into the expression for the $R^{2}$ from regressing $x_{i}$ on $\omega_{i}$, which we denote as $R_{x \omega}^{2} \equiv \operatorname{var}\left(\hat{\delta} \omega_{i}\right) / \operatorname{var}\left(x_{i}\right)$. The bound is then given by

$$
\frac{R_{x \omega}^{2}}{\tau^{2}}=\operatorname{var}\left(\hat{\delta} \omega_{i}\right) / \operatorname{var}\left(\chi_{i}\right)
$$

If $\omega_{i}$ explains none of the variance of $\varepsilon_{i}$, then (8) is an exact expression for the extent to which $\omega_{i}$ explains $\chi_{i}$. Otherwise, it is only an upper bound. Similarly, if $\tau_{m}^{2}-\tau^{2}>0$, an upper bound on the percent of the variation in $\varepsilon_{i}$ that comes from $\omega_{i}$ is given by

$$
\frac{R_{x \omega}^{2}}{1-\tau^{2}}
$$

Second, because our test is formulated as a difference between coefficients of determination, it is 
robust to misspecification of the basic investment- $q$ regression (1). For example, in Abel and Eberly (1994) the investment- $q$ relationship can be nonlinear because a wedge between the purchase and sale prices of capital causes the level of $q$ to affect the response of investment to $q$. For this problem to affect our tests, however, the source of nonlinearity needs to be correlated with our mispricing proxies because nonlinearity affects both the regression (1) and the version of (1) in which $x_{i}-\hat{\delta} \omega_{i}$ has been substituted in for $x_{i}$. We view this possibility as unlikely.

Third, the structure of our tests differs dramatically from those in previous studies, all of which are based on the null hypothesis that firms ignore the market. In contrast, this null is one of our two alternative hypotheses. Therefore, although previous findings that firms do not follow the market can be critiqued as resulting from low test power, any such findings on our part cannot.

\subsection{Applicability of the Model}

Is a linear errors-in-variables model appropriate for studying the effect of stock prices on investment? No econometric model ever represents reality perfectly, so the real question is whether this model captures the relevant features of the data. Our answer focuses the interpretation of the measurement error, $\varepsilon_{i}$, because if factors other than mispricing influence $\varepsilon_{i}$, and if our proxies for mispricing are correlated with these factors, our tests may simply pick up variation in these other factors.

To organize our discussion, we start with a candidate definition of fundamental investment opportunities as marginal $q$ - the manager's expectation of the future marginal product of capital. As discussed in Erickson and Whited (2000, 2006), three important links exist between marginal $q$ and an observable proxy. The first is the link between marginal $q$ and average $q$, which is the manager's expectation of the value of the capital stock divided by its replacement value. Although early work in $q$-theory, such as Hayashi (1982), shows that implausible conditions are necessary for marginal to equal average $q$, recent advances in $q$ theory, such as Cooper and Ejarque (2003), Caballero (1999), and Hennessy (2004), suggest that average $q$ - not marginal $q$-is the appropriate measure of fundamentals. Further, it is the variable that should be in an investment regression, as long as the regression contains cash flow and the debt-overhang correction in Hennessy (2004). We adopt this specification, thereby reducing the importance of the discrepancy between average and marginal $q$ as a source of variation in $\varepsilon_{i}{ }^{4}$ To the extent that this source of error remains, it would have to be correlated with our proxies for mispricing and information in order to affect our tests. 
We view this correlation as unlikely because this source of error primarily arises from technological considerations, whereas the proxies for mispricing and information depend on investor behavior.

The next link between fundamental investment opportunities and an observable proxy is the equality of average $q$ and Tobin's $q$, which is the financial markets' valuation of average $q$. A discrepancy between these two quantities arises if stock market inefficiencies create variation in the stock price that is irrelevant for investment. This component of $\varepsilon_{i}$ is the one on which we focus.

The third link arises because researchers estimate Tobin's $q$ from accounting data that do not adequately represent market and replacement values. These well-known mundane measurement issues admit a further interpretation of $\varepsilon_{i}$ as literal data recording error. Nonetheless, we view this interpretation as unimportant, given the evidence in Erickson and Whited (2006) that none of the available algorithms for estimating Tobin's $q$ improve measurement quality beyond the estimates produced directly from accounting data. They also find that most of the measurement error in Tobin's $q$ stems from the numerator, whose main driver is equity values. Thus, literal measurement difficulties are unlikely to contribute much to the variation in $\varepsilon_{i}$. Even if they do, these sorts of purely mechanical errors are unlikely to be correlated with our proxies for mispricing or information.

A further complication is the existence of two different ways to calculate Tobin's $q$. The first is the market-to-book ratio, which is the market value of assets divided by their book value. The second is what we call macro $q$, which is the sum of the market values of debt and equity less the value of current assets, all divided by the capital stock. The use of macro $q$ dates back to Summers (1981) and Fazzari, Hubbard, and Petersen (1988). Unlike the market-to-book ratio, which captures investment opportunities for all of the firm's assets, macro $q$ is designed to capture investment opportunities only in property, plant, and equipment. To streamline the discussion of our results, we primarily use the market-to-book ratio as our measure of Tobin's $q$ and the sum of capital expenditures and R\&D as our measure of investment. We view these two types of expenditure as the two most important contributors to firm assets. We consider other choices in our robustness section.

In sum, although a series of links joins Tobin's $q\left(x_{i}\right)$ to true investment opportunities $\left(\chi_{i}\right)$, the link most likely to be broken is the one due to stock market inefficiencies. Further, other possible sources of variation in $\varepsilon_{i}$ are unlikely to be correlated with our proxies for mispricing or information. Therefore, our testing strategy based on a signal extraction exercise is indeed appropriate. 


\section{Data and Summary Statistics}

This section describes our data sources. It then explains how we construct measures of financial constraints, mispricing, and information. It concludes by presenting summary statistics.

\subsection{Data and Variable Construction}

The data come from several sources. The first is the combined annual, research, and full coverage 2005 Standard and Poor's Compustat industrial files. We select the sample by first deleting any firm-year observations with missing data. Next, we delete any observations for which total assets, the gross capital stock, or sales are either zero or negative. Then for each firm we select the longest consecutive times series of data in which it did not undertake a merger greater than $25 \%$ of the book value of assets. We exclude firms with only one observation. Finally, we omit all firms whose primary SIC classification is between 4900 and 4999, between 6000 and 6999, or greater than 9000, because our model is inappropriate for regulated, financial, or quasi-public firms.

Data variables from Compustat are defined as follows: book assets is Item 6; the gross capital stock is Item 7; capital expenditures is Item 128; R\&D is item 46; cash flow is the sum of Items 18 and 14; net equity issuance is Item 108 minus Item 115; total long-term debt is Item 9 plus Item 34; total dividends is Item 19 plus Item 21; cash is Item 1; research and development costs are Item 46; inventories is Item 3; and sales is Item 12. The debt overhang correction represents the current value of lenders' rights to recoveries in default and is computed following Hennessy (2004). The numerator of the market-to-book ratio is the sum of the market value of equity (Item $199 \times$ Item 25 ) and total book assets minus the book value of equity (Item $60+$ Item 74 ), and the denominator is book assets. The numerator of macro $q$ is the market value of equity plus total long-term debt less inventories, and the denominator is the gross capital stock. All stock variables are measured at the beginning of the year and all flow variables are measured over the course of the year.

Our monthly and daily return data are from the 2005 CRSP tapes, and our data on analysts' earnings forecasts are from I/B/E/S. After merging the CRSP and I/B/E/S data with the Compustat data and after deleting the top and bottom $1 \%$ of our regression variables, we are left with a sample that contains between 2,684 and 3,891 observations per year, with a sample period that runs from 1991 to 2004. We obtain data on one of our measures of information from Duarte and Young (2007). After merging these data with the CRSP, Compustat, and I/B/E/S data and after 
deleting the top and bottom $1 \%$ of our regression variables, we are left with a sample that contains between 1,862 and 2,647 observations per year, over the same sample period. In the analysis that follows we use the larger sample whenever possible.

\section{$2.2 \quad$ Measures of Mispricing}

We use three measures of mispricing. Our use of multiple proxies is important, given that mispricing is difficult to measure. Our first proxy is a measure of belief heterogeneity. Denoted $S D E V$, this proxy is defined as the standard deviation of analysts' earnings-per-share forecasts. As argued in Panageas (2005a), Diether, Malloy, and Scherbina (2002), and Gilchrist, Himmelberg and Huberman (2005), dispersion of investor opinion combined with short-sales constraints can lead to equity overvaluation because pessimistic investors cannot trade on their beliefs. Further motivation for using this measure is in Sadka and Scherbina (2006), who explain that analysts disagree more about unfavorable earnings-related news. This evidence is tied to mispricing given the evidence in Hong, Lim, and Stein (2000) that bad news tends to be withheld from the market. Therefore, analyst disagreement is indirectly associated with stock prices that do not fully reflect bad news, that is, that are overpriced. This second interpretation is important inasmuch as short-sale constraints may be relevant only for small firms.

We obtain the analysts' forecast data from the Summary History file from I/B/E/S. The Summary History file is potentially less accurate than the Detail History file because of the presence of stale forecasts and coding errors. However, Diether, Malloy, and Scherbina (2002) report that both the Summary and Detail history files give very similar results, and consequently only report their results that use the Summary data. In addition, we follow Diether, Malloy, and Scherbina (2002) by collecting yearly rather than quarterly earnings forecasts, because this choice results in a larger sample. Because I/B/E/S forecasts are reported monthly and because the standard deviation of these forecasts grows as the forecast period lengthens, we construct an average standard deviation by scaling each forecast by the square root of the number of months between the estimate and the earnings announcement date. We then average the scaled forecasts. Finally, we rescale the standard deviation as a fraction of the capital stock instead of as a fraction of total shares. Our intent is to scale all of our variables by firm size, and the number of shares outstanding is an arbitrary number that does not necessarily measure the size of the firm. 
Because mispricing is transitory, a necessary (but not sufficient) condition for $S D E V$ to be a good proxy is the existence of low returns for high $S D E V$ firms. We find this pattern in our sample. The firms in the highest $S D E V$ quartile have on average negative returns in months 5 through 12 after the measurement of $S D E V$. This result has the further implication that mispricing, although transitory, persists long enough to open the avenue for firm investment to respond. In contrast, firms in other $S D E V$ quartiles exhibit no pronounced pattern of returns in either direction.

Our second measure of mispricing is the analysts' consensus estimate of earnings per share minus the realized level of earnings per share, which we denote $E S$. Once again we rescale by the capital stock. A positive value for this earnings surprise indicates an undervalued stock and a negative value indicates an overvalued stock. The existence of a nonzero earnings surprise implies that managers and market participants have different information about the firm. This lack of information flow means, by definition, that the stock is mispriced before the earnings announcement. One important issue that arises in measuring $E S$ is timing. The earnings announcement cannot occur before the time at which Tobin's $q$ is measured because the earnings announcement releases information. The ensuing market reaction then ameliorates any mispricing. We therefore consider the first earnings announcement that occurs from 1 to 5 months after the beginning of the fiscal year, which is when we measure Tobin's $q$. In results not reported we also examine longer time windows. For lengths of up to one year our results are robust. For lengths longer than one year our results are insignificant.

Our final measure of mispricing is the cumulative abnormal stock return from the beginning of the fiscal year to the end. This proxy in part follows Baker, Foley, and Wurgler (2007), who use negative returns subsequent to the measurement of Tobin's $q$ as a measure of mispricing, arguing that mispricing is a transient phenomenon and that firms with overvalued stocks ought to experience negative returns as the mispricing is corrected. We extend this idea by examining abnormal returns instead of raw returns to capture differences in risk across firms.

We reject several candidate measures of mispricing. For example, Polk and Sapienza (2007) use $R \& D$ intensity and accruals as measures of possible stock-market mispricing. However, these variables are chosen endogenously with investment and both are therefore likely to be correlated with true investment opportunities. This correlation would bias our results in the direction of not finding mispricing, even if mispricing were present. We also discard the direct measure of stockprice informativeness from Damodaran (1993) and Brisley and Theobald (1996), which measures the 
speed of adjustment of stock prices to information. The cross-sectional variation in this measure in our sample is quite low. Next, several authors have used share turnover as a proxy for mispricing. As argued in Stein (1996) and Panageas (2005a), stock market mispricing is most likely to affect firms whose investors have short-term horizons, a phenomenon that should manifest itself in high share turnover. However, the interpretation of share turnover is ambiguous, given the simple observation that liquid stocks are more likely to be correctly priced than illiquid stocks. None of our chosen proxies suffer strongly from these three problems of endogeneity, lack of variation, or ambiguity. We discuss the extent to which they may in the robustness section below.

\subsection{Measures of Information}

We examine two measures of private investor information, one measure of managerial private information, and one measure of public information. Our first proxy for private investor information is from Roll (1988), who considers the idiosyncratic variation in the firm's stock price. As explained and demonstrated in Durnev, Morck, and Yeung (2004), in the absence of firm-specific information, the firms' stock return moves only because of undiversifiable risk factors. On the other hand, the production of firm-specific information increases the idiosyncratic volatility of that firm's stock, rendering the return more weakly correlated with undiversifiable risk factors. Durnev, Morck, and Yeung (2004) measure idiosyncratic return variation as $\Psi \equiv \ln \left(\left(1-R_{i}^{2}\right) / R_{i}^{2}\right)$, in which $R_{i}^{2}$ is $R^{2}$ from the regression of firm-specific weekly returns on value-weighted market and value-weighted industry indices. The industry is defined at the three-digit SIC-code level. We hereafter refer to $\Psi$ as price nonsynchronicity. Chen, Goldstein, and Jiang (2007) provide a detailed survey of the literature that supports the idea that high idiosyncratic volatility is related to the existence of private investor information. They also survey several papers that argue and show that stock-price co-movement is related to a lack of private information in the stock price.

Our second measure of private information is a variant of the probability of informed trading, or $P I N$. Developed by Easley, Kiefer, and O'Hara (1996), PIN is based on estimation of a structural microstructure model in which trades can come from noise traders or from informed traders. Because PIN measures the probability of informed trading in a stock, and because informed traders trade on their information only if they think it is not yet publicly known, PIN is a theoretically appealing measure of the private information reflected in the stock price. PIN identifies periods of private 
information by isolating episodes of abnormal order flow imbalances. However, because buys and sells are highly correlated, PIN also captures liquidity. To address this issue, we turn to Duarte and Young (2007), who extend the model in Easley, Kiefer, and O'Hara by allowing for a correlation between buys and sells. Their model produces an adjusted PIN, or APIN, that only captures the informational component of the original PIN. Our APIN data are from Duarte and Young (2007).

Our measure of managerial private information is from Chen, Goldstein, and Jiang and is based on insider trading activities. This measure is constructed as the total number of insider stock transactions for the year divided by the total year's transactions. The intuition is that managers are more likely to trade the more private information they possess. We measure this activity using both buys and sells. Isolating buys produces almost identical results in the tests that follow, whereas isolating sells produces insignificant results, possibly because managers can also be motivated to sell for liquidity or diversification reasons. ${ }^{5}$ These data have only enough observations for us to run tests in the years 1997 to 2001, in which we have between 2459 and 2390 observations on both this measure and the relevant Compustat variables.

Finally, our measure of public information is the number of analysts covering a firm measured in the year preceding the measurement of Tobin's $q$. To the extent that analysts transfer information from managers to investors, high analyst coverage should indicate a small discrepancy between managerial and market expectations about investment opportunities.

\subsection{Measures of Financial Constraints}

Because financial constraints are endogenously determined with investment, we need an instrument. We use firm size, because small firms tend to be young, and young firms tend to face frictions in obtaining external capital. Indeed, Hennessy and Whited (2007) estimate that financing costs are almost twice as large for small firms as for large firms. Size therefore meets the requirement that an instrument be highly correlated with the endogenous variable it represents. Size can also be considered exogenous, because it is not a choice variable for the manager in the short run and is unlikely to depend on investment over the short period covered by our panel. Size is measured as the book value of total assets. ${ }^{6}$

We also use a previously formulated index of financial constraints, the $\mathrm{KZ}$ index, primarily to compare our results with those in the rest of the literature. This index is from Kaplan and Zingales 
(1997), who examine the annual reports of the 49 firms in Fazzari, Hubbard, and Petersen's (1988) "constrained" sample. They use this information to rate the firms on a financial constraints scale, and the index is the fitted value of an ordered logit of this scale on observable firm characteristics. Several authors have used these logit coefficients on data from a broad sample of firms to construct a "synthetic KZ index" to measure financial constraints. It is constructed as

$$
-1.001909 C F+3.139193 T L T D-39.36780 T D I V-1.314759 C A S H+0.2826389 Q,
$$

in which $C F$ is the ratio of cash flow to book assets, $T L T D$ is the ratio of total long-term debt to book assets, $T D I V$ is the ratio of total dividends to book assets, $C A S H$ is the ratio of the stock of cash to book assets, and $Q$ is the market-to-book ratio. As argued in Baker, Stein, and Wurgler (2003), financially constrained firms issue more equity than their unconstrained counterparts. Therefore, they interpret this index of financial constraints as an index of equity dependence. In what follows we prefer to focus on financial constraints, which we have defined precisely, instead of on equity dependence, which is a much harder concept to define. Following Baker, Stein, and Wurgler (2003), we exclude the $Q$ term when computing the synthetic KZ index for each firm. One drawback of the $\mathrm{KZ}$ index is that it is unlikely to be exogenous to the investment decision because it is a function of endogenously determined variables such as cash flow and dividend payout.

\subsection{Summary Statistics}

Summary statistics for the sample stratified into quartiles by size and the KZ index are in Table 1. The first panel contains the sort on size. Small firms clearly do not finance with debt, and they issue equity much more often and in greater quantities than large firms. Further, few of the small firms have bond ratings, and the incidence of bond ratings increases monotonically with size. Finally, the small firms have better investment opportunities, as captured by Tobin's $q$ and the market-to-book ratio, and they invest more than large firms, despite much lower cash flow. These patterns reinforce the idea that firm size is a good indicator of the tendency of small firms to require outside finance. Also, given that debt finance is generally less costly than external equity finance, size is also a good indicator of the higher financing costs faced by small firms.

The next panel contains the results for the KZ index. High-KZ firms use much more debt than low-KZ firms, they issue equity slightly less often than low-KZ firms, and the size of issuance as a percent of total assets is nearly identical across the different $\mathrm{KZ}$ groups. Further, the distribution 
of bond ratings across the four $\mathrm{KZ}$ quartiles is quite even, and no discernible pattern appears in the distribution of total assets. The KZ index clearly does not capture the notion of equity dependence, nor does it capture the notion of financial constraints. For example, as also found in Whited and $\mathrm{Wu}$ (2006), high-KZ firms invest at the same rate as their unconstrained counterparts despite substantially lower values of Tobin's $q$. This finding of possible overinvestment raises the issue of interpretation of the result in Baker, Stein, and Wurgler (2003) of a positive correlation between the KZ index and investment- $q$ sensitivity. They claim this pattern means that the investment of constrained, equity-dependent firms responds to stock-price movements. This evidence suggests that they have instead uncovered a positive relation between investment- $q$ sensitivity and the tendency of firms to overinvest and use debt. Because of such difficulties in interpreting the KZ index, in what follows we primarily rely on size, only using the KZ index to place our results in the literature.

Table 2 presents summary statistics for the sample stratified into quartiles by our information proxies. The first panel contains the results for price nonsynchronicity $(\Psi)$ and the second for $A P I N$. We find no strong association between Tobin's $q$ and either $\Psi$ or APIN. Tobin's $q$ rises slightly with $\Psi$ and falls slightly with $A P I N$. This result is consistent with the notion that our proxies only represent the amount of information in the stock price instead of any specific positive or negative information. Next, note the decrease in firm size, decrease in bond-rating incidence, and increase in equity issuance as $\Psi$ rises. In contrast, we find a lack of association between $A P I N$ and either debt or equity financing. We do, however, continue to find a negative association between APIN and firm size. The smaller the firm, the more private investor information is produced. The third panel contains summary statistics for the sample stratified by a measure of public information: the number of analysts covering a firm. Larger, more profitable firms have greater analyst coverage. In contrast to the large firms in Table 1, however, these large firms have relatively high Tobin's $q \mathrm{~s}$; in other words, analysts tend to cover large growth firms. Finally, it appears that financing patterns are largely unrelated to analyst coverage. The fourth panel presents results for subsamples sorted by our measure of managerial information: INSIDE. Firms with a great deal of insider trading activity are smaller, have lower $q \mathrm{~s}$, and tend to rely less on equity finance.

Table 3 contains summary statistics for the sample stratified into quartiles by our mispricing proxies. The first panel presents the results for $S D E V$, the standard deviation of analysts' earnings estimates. In contrast to the case of the information proxies, Tobin's $q$ and investment both increase 
with this proxy for overvaluation. This finding is reassuring in that the strong cross-sectional association between $S D E V$ and Tobin's $q$ implies that our strategy of projecting Tobin's $q$ on $S D E V$ is likely to be fruitful. Although consistent with overpricing, the positive association between $S D E V$ and Tobin's $q$ need not necessarily imply overpricing. There is not enough information in simple summary statistics to make such an inference. Finally, high- $S D E V$ firms also are small and characterized by a low incidence of bond ratings, low cash flow, and a strong tendency to rely on equity finance. This pattern is similar to that seen for the firms sorted by the $\Psi$, which brings up the issue of whether $\Psi$ is also proxying for mispricing. We discuss and deal with this issue below.

The next two panels report summary statistics for our other two measures of mispricing: the earning surprise $(E S)$ and the abnormal return $(A B R E T)$. The results are broadly similar, although Tobin's $q$ rises with ES more strongly than it does with $A B R E T$. In general, however, our three measures of mispricing appear to be classifying firms in a similar manner. Indeed, they are all positively correlated, with correlation coefficients ranging between 0.20 and 0.34 .

\section{Results}

This section is divided into three parts. The first discusses the results of our specification tests. The second presents the results from our tests of the effects of information and mispricing on investment. The third conducts robustness checks.

\subsection{Specification Tests}

We start with a result that is important for all of the evidence that follows. We rarely reject the overidentifying restrictions from yearly estimates underlying the averages presented in the tables that follow. This result is critical because possible model misspecification, such as model nonlinearity, heteroskedasticity, or an error-regressor correlation, could lead to biased estimates of $\tau^{2}$. For example, it is possible that when making investment decisions, the manager pays attention to information not captured by the stock price, perhaps following his own empire-building motives. This scenario can manifest itself in our econometric model as an omitted variable, which induces a correlation between $u_{i}$ and either $\chi_{i}$ or $z_{i}$ if the omitted variable is correlated with $\chi_{i}$ or $z_{i}$. Similarly, suppose firms announce major capital-expenditure campaigns. In this case, $u_{i}$ is correlated with $\chi_{i}$ because capital expenditures cause the stock-price reaction. Finally, a correlation between 
$\chi_{i}$ and $\varepsilon_{i}$ may arise because investors make decisions based on extrapolative expectations that are in part based on fundamentals, as in Barberis, Schleifer, and Vishny (1998). The mispricing that ensues from this type of investor behavior is captured in $\varepsilon_{i}$ but is also correlated with fundamentals. Correlation between $\chi_{i}$ and $\varepsilon_{i}$ may also arise if stock market bubbles tend to appear at times of structural change in the economy. Therefore, better fundamental investment opportunities may be associated with larger values for $\varepsilon_{i}$.

However, the lack of rejections indicates that these possibilities are not likely, especially in light of the evidence in Erickson and Whited (2000) that the test of overidentifying restrictions has good finite-sample power to detect even small amounts of misspecification. On an intuitive level this good power makes sense because these estimators are based on long polynomials, which are by nature fragile. Any violation of the independence or linearity assumptions that define the model gets magnified as it propagates through the system. In sum, even though the classical errors-in-variables model is not a perfect representation of the relationship between investment and $q$, our specification testing indicates that it is a useful approximation, as well as an acceptable structure for identifying the effects of unobservable variables.

\subsection{Information and Mispricing}

We start with the hypothesis that $\tau^{2}$ increases in the amount of information in the stock price. To this end we sort the sample into quartiles based on $\Psi$ and APIN. The results are in Table 4. The first column presents the OLS estimates of the coefficient on Tobin's $q$ in a regression of the ratio of investment to assets on Tobin's $q$, the ratio of cash flow to assets, and the Hennessy (2004) overhang correction. The other coefficient estimates have been suppressed for brevity. As in Chen, Goldstein, and Jiang (2007), these coefficients rise substantially with the amount of information in the stock price. The rest of the table presents the results from estimating (1) and (2) via the fourth-order estimator in Erickson and Whited (2000). This particular estimator performs best for estimating $\tau^{2}$ in a Monte Carlo simulation in the Appendix. In contrast to the OLS results, the measurement-errorconsistent GMM estimates of the coefficient on Tobin's $q$ rise only slightly. Because the attenuation bias in the OLS coefficient on Tobin's $q$ is approximately proportional to $\tau^{2}$, the difference in these two patterns can be seen in the estimates of $\tau^{2}$, which rise with informativeness. Indeed for both $\Psi$

and $A P I N$ the estimate of $\tau^{2}$ is significantly smaller in the low-information group than it is in the 
high-information group. This result confirms our hypothesis that price informativeness matters for investment and bolsters the results in Chen, Goldstein, and Jiang (2007). Their finding of higher investment- $q$ sensitivity for firms whose stock prices contain a great deal of private information could possibly be contaminated by correlations between private information and financial or technological frictions, which are also important determinants of investment- $q$ sensitivity. In contrast, $\tau^{2}$ is not affected by these considerations. In this particular case, it appears that the potentially misleading method of examining investment- $q$ sensitivity has been innocuous.

One difficulty with the interpretation of these results lies in the possibility that $\Psi$ and $A P I N$ capture public information or private managerial information. To deal with these possibilities, we use our proxies for public information and for private managerial information. Specifically, we separate out the top and bottom thirds of our sample based on each of these measures and then examine whether the results in Table 4 hold up within groups of firms that are relatively homogeneous along the lines of managerial or public information. These results are in Table 5. The upper left quadrant contains results for firms with high analyst coverage. As in Table 4, for both $\Psi$ and APIN we find higher estimates of $\tau^{2}$ for the high-information groups, although the difference is significant only in the case of $A P I N$. Qualitatively similar results are in the other three quadrants of the table, which correspond to groups with low analyst coverage, high insider trading, and low insider trading. These differences are significant in half of the cases. Although these results are somewhat weaker than those in Table 4, this difficulty is a product of smaller sample sizes in these finer sample splits; and we therefore conclude that our results are unlikely to be an artifact of either $\Psi$ or APIN capturing public or managerial information. A similar result is in Chen, Goldstein, and Jiang (2007). ${ }^{7}$

We next turn to our tests for the effects of mispricing on investment. The first set of these results is in Table 6. As in Tables 4 and 5, we report OLS estimates of the coefficient on $q$ and the GMM estimates of the $q$ coefficient and $\tau^{2}$. We also report estimates of four versions of $\tau_{m}^{2}-\tau^{2}$. We compute this quantity for each of our mispricing proxies separately, as well as for all three at once. Recall that $\tau_{m}^{2}-\tau^{2}>0$ implies that mispricing is irrelevant for investment and that $\tau_{m}^{2}-\tau^{2}<0$ implies that mispricing is relevant for investment.

The first line of this table presents the results for the full sample. All of the estimates of $\tau_{m}^{2}-\tau^{2}$ are positive, and the one that uses all three mispricing proxies is marginally significant, indicating a general tendency of firms to ignore mispricing when making investment decisions. 
The weakness of this result, however, begs the question of the existence of any heterogeneity in the sample with regard to the response of investment to mispricing. Therefore, following Baker, Stein, and Wurgler, we first examine whether this response varies with measures of financial constraints. The next panel of Table 6 presents results from sorting the sample into quartiles based on our instrument for financial constraints - firm size. All sample splits are done on the basis of once-lagged variables to mitigate endogeneity concerns. The OLS estimates of the slope coefficient on true $q$ vary little with firm size, whereas the GMM estimates decrease with size. At the very least this result indicates the fragility of previous findings in the literature of a positive relation between investment- $q$ sensitivity and equity dependence or financial constraints. This evidence also shows that investment- $q$ sensitivity must depend on a variety of factors other than the cost of external finance. Otherwise, some relation would have been evident, if one accepts the arguments in Baker, Stein, and Wurgler (2003) that investment- $q$ sensitivity ought to increase with financial constraints. In contrast to the results on investment- $q$ sensitivity, $\tau^{2}$ increases sharply with size. ${ }^{8}$ In other words, the component of Tobin's $q$ that is relevant for investment is smaller for small firms than for large firms. This result suggests that smaller firms are more likely to have investment that responds to price informativeness. The result is not surprising, given the strong negative association in Table 2 between size and informativeness, and it brings up the connection between mispricing and informativeness. These two phenomena are related dynamically inasmuch as mispricing provides incentives for market participants to produce information and inasmuch as information production reduces mispricing. Because we use annual data, because mispricing is likely to be transitory, and because any subsequent information production may be rapid, examination of $\tau^{2}$ tells us little about any differences in these groups of firms with regard to the relation between mispricing and investment.

To answer this question, therefore, we examine the mispricing tests. First, note that all three mispricing proxies produce qualitatively similar results. In the group of the smallest firms we find negative estimates of $\tau^{2}-\tau_{m}^{2}$ for all of the proxies, although only one is marginally significant. This result suggests that small firms may exploit overpriced equity to relieve a binding finance constraint, but the evidence is not strong. We find no significant estimates of $\tau^{2}-\tau_{m}^{2}$ in the middle size quartiles, and estimates significantly greater than zero in the large size quartile. This last result implies that the component of Tobin's $q$ caused by mispricing is not relevant for the investment of large firms. In the case in which we use all three proxies at once, we can infer via (9) that up to $51 \%$ of the 
variation in $\varepsilon_{i}$ is due to variation in the mispricing proxies . Two reasons large firms ignore market mispricing are their tendency to self-finance and the existence of underwriting costs for seasoned equity issues. Even if equity values are too high, they must be high enough to overcome these costs. Further, although the manager may issue equity when he perceives the stock price as too high, he need not spend the proceeds on capital goods if investment incurs fixed costs.

The bottom half of the table presents results from subsamples sorted by the KZ index. As in Baker, Stein, and Wurgler (2003), we find that the OLS estimates of the sensitivity of investment to $q$ increases with the KZ index. The evidence from the estimates of $\tau^{2}-\tau_{m}^{2}$ is mixed. We find weak evidence in the most constrained group that mispricing is not relevant for investment, and we find even weaker evidence in the least constrained group that mispricing is relevant for investing. The first result makes sense in a world in which mispricing operates through equity issuance because the KZ-constrained firms tend to rely more on debt than equity. Nonetheless, the two main messages from the bottom panel are that investment- $q$ sensitivity does not do a good job of indicating whether firm investment reacts to mispricing and that the lack of information about financing constraints in the KZ index produces, not surprisingly, inconclusive results.

We next revisit the empirical result in Polk and Sapienza (2006) that mispricing affects investment more when mispricing is more severe. Accordingly, we split the sample into quartiles based on $S D E V, E S$, and $A B R E T$. The results are in Table 7. First, we find that both the OLS and GMM estimates of investment- $q$ sensitivity vary little across the subsamples. The more interesting evidence, however, is the mispricing tests. No matter which proxy we use to sort the sample, we find that for firms with high overpricing, investment does not respond to this overpricing. We reemphasize that because ignoring mispricing is one of our alternative hypotheses, this result cannot be a product of low power. The tests point to an economically strong effect. For example, the estimate of 0.166 found in the overpriced group sorted by $A B R E T$ implies that up to $30 \%$ of the variation in $\varepsilon$ can be attributed to the overpricing proxies. Our results from sorting on ES and ABRET are somewhat different in that we find weak evidence that the investment of firms with underpriced stock responds to this underpricing. In sum, we cannot corroborate previous findings that mispricing is more relevant for the investment of firms whose stocks suffer from the most mispricing. 


\subsection{Robustness}

We examine two major and several minor robustness issues. The first major issue is alternative interpretations of our proxies for information and mispricing. We start with price nonsynchronicity, $\Psi$. Ang, Hodrick, Xing, and Zhang $(2006,2008)$ find evidence that firms with high idiosyncratic risk have low returns. This pattern is also evident in our sample. The high- $\Psi$ quartile has average negative monthly returns in 5 of the 12 months following the measurement of $\Psi$. Few negative returns are evident in the other $\Psi$ quartiles. This finding suggests two possibilities with the potential to muddy the interpretation of our results. First, low returns for high- $\Psi$ firms might indicate overpricing. Idiosyncratic risk has been used to represent overpricing for other reasons as well. Baker, Coval, and Stein (2007) use idiosyncratic risk as a measure of the slope of a stock's demand curve. If arbitrage entails risk, then the usual arbitrage arguments that lead stocks to be perfect substitutes for one another fail. In this case firms with more idiosyncratic risk are less perfect substitutes for other stocks, and their demand curves slope downward. To the extent that prices drift up over time, a downward sloping demand curve can also be a proxy for overpricing. Second, the evidence in Ang et al. $(2006,2008)$ that idiosyncratic risk is priced implies that some underlying unobservable, undiversifiable risk factor might be driving our results.

To address these issues we turn to Hou and Moskowitz (2005), who find that the pricing of idiosyncratic risk is confined to high-delay firms; that is, firms for whom the lagged market return is significant in a CAPM regression. We estimate delay as in Hou and Moskowitz (2005), remove the top decile of firms sorted on delay, and rerun our tests. After removing the high delay firms, our results remain almost unchanged, and the negative returns in the high $\Psi$ quartile disappear, which indicates that overpricing is less of a concern. It is, therefore, unlikely that overpricing or an unobserved risk factor is driving our results that use $\Psi$ as a proxy for price informativeness.

Idiosyncratic risk has also been used to proxy for asymmetric information, as in Dierkens' (1991) study of equity issues. This interpretation is unlikely to be important in our sample, however. If it were, we ought to have observed estimates of $\tau^{2}$ decreasing with $\Psi$ and APIN instead of increasing.

One of our proxies for mispricing, $S D E V$, also allows important alternative interpretations. First, analysts' differences of opinion might stem from uncertainty surrounding the firm's operations rather than from differing prior beliefs. This explanation is, however, unlikely to be important 
because, as demonstrated in Leahy and Whited (1996), Tobin's $q$ is decreasing in a forward-looking measure of uncertainty. In contrast, we find that $S D E V$ and Tobin's $q$ are positively correlated. It is therefore unlikely that $S D E V$ is driven primarily by uncertainty because in this case we ought to have found a negative relation between Tobin's $q$ and $S D E V$. This evidence also alleviates the concern that $S D E V$ can be a proxy for idiosyncratic risk, as in Johnson (2004). Finally, given that our other mispricing proxies produce qualitatively similar results, we feel confident that we have captured the notion of mispricing with these proxies.

The second major issue is our choice of measures of investment and Tobin's $q$. The literature in this area has made a variety of choices, with most finance papers using the ratio of capital expenditures to assets along with the market to book ratio, and with most macroeconomics papers using the ratio of capital expenditures to the capital stock along with macro $q$. Given the wide variety of practices, to add credibility to our results, we reexamine the results in Tables 4 and 6 using three combinations of Tobin's $q$ and investment: market-to-book with capital expenditures, macro $q$ with capital expenditures, and, for purposes of comparison, our original choice of marketto-book with the sum of capital expenditures and R\&D.

The left side of Figure 3 contains plots of the OLS and GMM coefficients on $q$ and of $\tau^{2}$ as a function of the $\Psi$ quartiles for each investment- $q$ combination. In the first panel, our result of increasing investment- $q$ sensitivity is robust to the use of the combination of capital expenditures and market-to-book, but not to the use of macro $q$. The second and third panels, however, show that our results concerning the GMM estimates of the $q$ coefficient and of $\tau^{2}$ are robust. One pattern of interest is the low estimates of $\tau^{2}$ for the combination of capital expenditures and market-to-book. This result is also in Whited (2001), and it supports the notion that market-to-book varies because of changes in the opportunities for investing in many different assets. The variation unrelated to capital expenditures ends up in the measurement error, $\varepsilon_{i}$, thereby lowering $\tau^{2}$. The right side of Figure 3 presents analogous results for the sample split by APIN. In this case, only the results for $\tau^{2}$ are robust. We conclude that examining coefficients on $q$ can be sensitive to the way in which investment and Tobin's $q$ are measured. In contrast, examining patterns in $\tau^{2}$ is not.

Figure 4 reexamines our results in Table 6. It is analogous to Figure 3, except that the bottom panels plot $\tau^{2}-\tau_{m}^{2}$ for the case in which all three mispricing proxies are used at once. The left side presents results for the size split. For all three investment- $q$ combinations, the OLS and GMM 
coefficients on $q$ vary little across size quartiles. In the third panel, the mispricing tests are almost identical for our original investment- $q$ choice and for the combination of macro $q$ and capital expenditures. Both sets of tests increase with size and are significantly greater than zero for the largest firms. In contrast, the results for the combination of capital expenditures and market-to-book are nonmonotonic and insignificant. The reason is the low and imprecise estimates of $\tau^{2}$ for this combination. The right side presents results for the sample split by the KZ index. The first panel shows that the result in Baker, Stein, and Wurgler (2003) of increasing investment- $q$ sensitivity is not robust to the use of macro $q$. The results in third panel on the right are similar to those for the size split. Again we find almost no difference in the results when we switch to macro $q$, but we produce noisy estimates of $\tau^{2}-\tau_{m}^{2}$ based on the combination of market-to-book and capital expenditures. We conclude from these figures that both of our tests based on $\tau^{2}$ are much less sensitive to the use of different measures of investment and Tobin's $q$ than are tests based on investment- $q$ sensitivity. ${ }^{9}$

We now turn to several miscellaneous robustness issues. First, Tobin's $q$ might differ from true investment opportunities more for small firms than for large firms because small firms have more intangible capital that is not on the books. This problem inflates macro $q$ because intangibles cannot be subtracted from the numerator and it inflates market-to-book because intangibles are not included in the denominator. In this case groups of firms with more intangible capital ought to have lower estimates of $\tau^{2}$. One feature of our econometric model that mitigates this concern is the intercept in the measurement equation (2). To the extent that the intercept captures the effects of intangible capital, this source of bias does not affect our estimates of $\tau^{2}$. To examine this possibility in an extreme case, we isolate three industries in which we expect human capital to constitute a large component of total assets: electronic equipment (SIC 35), instruments (SIC 36), and business services (SIC 73). We also isolate three industries in which we expect human capital to be inconsequential: stone, glass, clay, and concrete products (SIC 32); lumber and wood products (SIC 24); and agriculture (SIC's 01, 02, and 07). The estimate of $\tau^{2}$ for the human-capital-intensive industries is 0.489 , and the estimate of $\tau^{2}$ for the human-capital unintensive industries is 0.514 . Both estimates differ significantly from zero, but not from each other. This similarity means that it is unlikely that our results are an artifact of the presence of intangible capital.

A further concern is the possibility that mispricing and incentives to produce information depend on firm characteristics. For example Dow, Goldstein, and Guembel (2007) model the possibility that 
speculators have a greater incentive to produce information about ex-ante profitable projects. In terms of our methodology this type of behavior introduces an error-regressor correlation into our regressions of Tobin's $q$ on our mispricing proxies. Therefore, the residuals from the regressions still contain information about mispricing that would have been purged in the absence of an errorregressor correlation. This problem therefore lowers the power of our tests based on the difference $\tau^{2}-\tau_{m}^{2}$. However, low power is of little concern because we do find many significant results.

Finally, several of our estimates of $\tau^{2}-\tau_{m}^{2}$ are insignificantly different from zero. These results are difficult to interpret as evidence that firms do not respond to the market because the results could possibly arise in instances in which firms pay attention to some market signals and ignore others. To deal with this issue, we formulate a slightly different test based on the difference $\operatorname{var}\left(\chi_{i}\right)_{m}-\operatorname{var}\left(\chi_{i}\right)$, in which the subscript $m$ indicates that a mispricing proxy has been partialled out of $x_{i}$. These tests are easier to interpret. The null hypothesis is that mispricing does not matter, and the difference in the estimated variances is therefore never greater than zero. The null is rejected if it is significantly less than zero. Interestingly, when we use this test, we find results that are qualitatively similar to those reported in Tables 4 through 6.

Although this test is easier to interpret, it confers a serious disadvantage relative to our original test. In Monte Carlo experiments identical to those reported in the Appendix, we find that the parameter $\operatorname{var}\left(\chi_{i}\right)$ is estimated much less precisely than $\tau^{2}$. This lack of precision produces a slight tendency for this test to overreject the null in finite samples. We have therefore opted for the more conservative test based on $\tau^{2}$.

\section{Conclusion}

We ask whether firms follow the market; that is, whether their investment depends on the amount of mispricing or private information in their stock prices. This question is particularly important in light of recent debate among policy makers over whether central banks should try to target stock markets. This sort of targeting makes sense only if the stock market affects real economic activity. Our innovation in examining this old question lies in using an econometric errors-in-variables remedy to separate variation in the stock price that is relevant for investment from variation that is not. We conduct two types of tests that exploit this decomposition. First, we see how the relevant variation depends on proxies for price informativeness. Second, we remove variation in the stock price that 
comes from proxies for mispricing. The variation thus removed is either relevant or irrelevant for investment, and our errors-in-variables technique can identify both of these cases.

These methods are quite different from those that have been used previously; accordingly, some the results are also different. In contrast to much of the recent literature that finds strong support for the idea that market mispricing influences investment, we find that firms with high levels of mispricing and large firms consider mispricing irrelevant for investment. We find only weak evidence that firms suffering from financial constraints make investment decisions with market mispricing in mind. Our results concerning price informativeness, however, confirm the previous results in Luo (2005) and Goldstein, Chen, and Jiang (2007) that investment decisions are guided by private information embedded in the stock price.

The final contribution of the paper is its econometric methodology. It can shed light not only on the link between stock prices investment but also on the links between stock prices and many other corporate decisions, such as equity issuance, employment, and capital structure. 


\section{Appendix}

For reference we reproduce (1) and (2) from the text

$$
\begin{aligned}
& y_{i}=z_{i} \alpha+\chi_{i} \beta+u_{i} \\
& x_{i}=\gamma_{0}+\chi_{i}+\varepsilon_{i} .
\end{aligned}
$$

$\varepsilon_{i}$ is a mean-zero error independent of $\left(u_{i}, z_{i}, \chi_{i}\right)$, and $u_{i}$ is independent of $\left(\chi_{i}, z_{i}\right)$. The intercept $\gamma_{0}$ allows for the nonzero means of some sources of measurement error. The EW estimators also require the assumption that $\left(\varepsilon_{i}, u_{i}, z_{i}, \chi_{i}\right), i=1, \ldots, n$, are $i . i . d$., that the residual from the projection of $\chi_{i}$ on $z_{i}$ has a skewed distribution, and that $\beta \neq 0$. The last two assumptions are required for estimator identification and are testable.

Let $\left(\dot{y}_{i}, \dot{x}_{i}, \dot{\chi}_{i}\right)$ be the residuals from the linear projection of $\left(y_{i}, x_{i}, \chi_{i}\right)$ on $z_{i}$. Then (10) and (11) can be written as

$$
\begin{aligned}
& \dot{y}_{i}=\beta \dot{\chi}_{i}+u_{i} \\
& \dot{x}_{i}=\dot{\chi}_{i}+\varepsilon_{i} .
\end{aligned}
$$

If we square (12), multiply the result by (13), and take unconditional expectations of both sides, we obtain

$$
E\left(\dot{y}_{i}^{2} \dot{x}_{i}\right)=\beta^{2} E\left(\dot{\chi}_{i}^{3}\right)
$$

Analogously, if we square (13), multiply the result by (12), and take unconditional expectations of both sides, we obtain

$$
E\left(\dot{y}_{i} \dot{x}_{i}^{2}\right)=\beta E\left(\dot{\chi}_{i}^{3}\right)
$$

As shown in Geary (1942), if $\beta \neq 0$ and $E\left(\dot{\chi}_{i}^{3}\right) \neq 0$, dividing (14) by (15) produces a consistent estimator for $\beta \equiv \beta^{2} E\left(\dot{\chi}_{i}^{3}\right) / \beta E\left(\dot{\chi}_{i}^{3}\right)$. The innovation in Erickson and Whited (2002) consists of combining the information in moment equations of order two up through seven via GMM to obtain a more efficient estimator for $\beta$. Note that $\alpha_{1}$ can be recovered by the identity

$$
\alpha_{1}=\mu_{y}-\beta \mu_{x}
$$

in which $\left(\mu_{y}, \mu_{x}\right)$ are the slope coefficients in the projection of $\left(y_{i}, x_{i}\right)$ on $z_{i}$. 
The coefficients of determination $\left(R^{2}\right.$ 's) for (10) and (11) are calculated as

$$
\begin{aligned}
\rho^{2} & =\frac{\mu_{y}^{\prime} \operatorname{var}\left(z_{i}\right) \mu_{y}+E\left(\dot{\chi}_{i}^{2}\right) \beta^{2}}{\mu_{y}^{\prime} \operatorname{var}\left(z_{i}\right) \mu_{y}+E\left(\dot{\chi}_{i}^{2}\right) \beta^{2}+E\left(u_{i}^{2}\right)} \\
\tau^{2} & =\frac{\mu_{x}^{\prime} \operatorname{var}\left(z_{i}\right) \mu_{x}+E\left(\dot{\chi}_{i}^{2}\right)}{\mu_{x}^{\prime} \operatorname{var}\left(z_{i}\right) \mu_{x}+E\left(\dot{\chi}_{i}^{2}\right)+E\left(\varepsilon_{i}^{2}\right)} .
\end{aligned}
$$

Equation (17) is exactly equivalent to equation (5) in the text.

To allay skepticism about empirical results produced by unusual estimators on fairly small samples, we report a Monte Carlo simulation that uses artificial data similar to our real data, in terms of both sample size and observable moments. The specific purpose of these simulations is threefold. First, we wish to determine which of the Erickson and Whited GMM estimators is best for $\tau^{2}$. Second, we wish to estimate the finite-sample two-sided $5 \%$ critical values for the t-statistics produced with the Fama-MacBeth standard errors. Third, we wish to ascertain whether our tests have power to detect mispricing and price informativeness if our measures of these two phenomena are noisy.

For the first two goals we generate 10,000 simulated panels with a cross-sectional sample size equal to 336, the size of the smallest cross section in any of our estimations. We set the length of the panel equal to the length of our actual panel. We set the parameters $\beta, \rho^{2}$, and $\tau^{2}$ approximately equal to the averages of the corresponding GMM estimates from Table 3. For brevity, we omit perfectly measured regressors, which are an embellishment that has little effect on the Monte Carlo results. Each observation is of the form $\left(y_{i}, x_{i}\right)$, in which we generate $\left(y_{i}, x_{i}\right)$ according to (1)-(2) so that $y_{i}$ and $x_{i}$ have, on average over the simulation samples, first and second moments equal to, serial correlation comparable with, and higher-order moments comparable with the corresponding average sample moments from our real data.

For the third-, fourth-, and fifth-order GMM estimators, Table 8 reports the mean value of an estimator, its mean absolute deviation (MAD) and the probability that an estimate is within $20 \%$ of its true value. Table 8 shows that the fourth-order GMM estimator (GMM4) gives the best estimates of all parameters in terms of bias, MAD, and probability concentrations.

Our next set of simulations examines the effects on our tests of poor proxies for mispricing. We consider two alternative scenarios. In the first we allow $\chi_{i}$ (true unobserved $q$ ) to be a linear 
function of a "mispricing" or "price informativeness" variable, $m_{i}$, according to

$$
\chi_{i}=m_{i}+\eta_{i}
$$

in which $\eta_{i}$ is an i.i.d random variable. This scenario describes a situation in which mispricing matters for true investment opportunities. In the second we allow $\varepsilon_{i}$ (the discrepancy between true and observable $q$ ) to be a function of $m_{i}$ according to

$$
\varepsilon_{i}=m_{i}+\eta_{i}
$$

In other words $m_{i}$ is a component of $\varepsilon_{i}$ and therefore affects observable $q$ but not true investment opportunities. We set the coefficients of determination of (18) and (19) equal to 0.25. Our actual observed variable $\hat{m}_{i}$ is then a function of $m_{i}$, according to

$$
\hat{m}_{i}=m_{i}+\hat{\eta}_{i}
$$

We allow the coefficient of determination of (20) to range from 0.2 to 1 , corresponding to situations that range from those in which $\hat{m}_{i}$ is a poor proxy to those in which $\hat{m}_{i}$ is a good proxy for $m_{i}$.

For each scenario we generate 10,000 simulated panels and calculate the difference $\tau_{m}^{2}-\tau^{2}$, and we then count the number of times the t-test associated with $\tau_{m}^{2}-\tau^{2}$ exceeds the nominal two-sided $5 \%$ critical value for the null that $\tau_{m}^{2}-\tau^{2}=0$. In the first scenario, which depicts managerial attention to mispricing, we find that the t-test produces rejections from $41 \%$ to $93 \%$ of the time as the coefficient of determination of (20) ranges from 0.2 to 0.8 . In the second scenario, which depicts managerial inattention to mispricing, we find that the t-test produces rejections from $39 \%$ to $92 \%$ of the time as the coefficient of determination of (20) ranges from 0.2 to 0.8 . We conclude that noise in our proxies for mispricing or price informativeness only lowers the power of our tests, and that even this lower power can be useful to detect mispricing. 


\section{References}

Abel, A. B., and J. Eberly, 1994, "A Unified Model of Investment under Uncertainty," American Economic Review 84, 1369-1384.

Almeida, H., and M. Campello, 2007, "Financial Constraints, Asset Tangibility, and Corporate Investment," Review of Financial Studies, 20, 1429-1460.

Ang, A., R. J. Hodrick, Y. Xing, and X. Zhang, 2006, "The Cross-Section of Volatility and Expected Returns," Journal of Finance 51, 1, 259-299.

Ang, A., R. J. Hodrick, Y. Xing, and X. Zhang, 2008, "High Idiosyncratic Volatility and Low Returns: International and Further U.S. Evidence," Journal of Financial Economics, forthcoming.

Baker, M. P., J. Coval, and J. C. Stein, 2007, "Corporate Financing Decisions When Investors Take the Path of Least Resistance," Journal of Financial Economics 84, 266-298.

Baker, M. P., C. F. Foley, and J. Wurgler, 2007, "Multinationals as Arbitrageurs? Stock Market Valuations and Foreign Direct Investment," Review of Financial Studies, forthcoming

Baker, M. P., J. C. Stein, and J. Wurgler, 2003, "When Does the Market Matter? Stock Prices and the Investment of Equity Dependent Firms," Quarterly Journal of Economics 118, 969-1006.

Barberis, N., A., Schleifer, and R. Vishny, 1998, "A Model of Investor Sentiment," Journal of Financial Economics 49, 307-343.

Blanchard, O. J., C. Rhee, and L. H. Summers, 1993, "The Stock Market, Profit, and Investment," Quarterly Journal of Economics 108, 115-136.

Bosworth, B., 1975, "The Stock Market and the Economy," Brookings Papers on Economic Activity $2,257-290$.

Brisley, N., and M. Theobald, 1996, "A Simple Measure of Price Adjustment Coefficients: A Correction," Journal of Finance 51, 381-382.

Caballero, R. J., 1999, "Aggregate Investment." In: Taylor, J.B., M. Woodford (eds.),Handbook of Macroeconomics, Vol. 1A. North Holland, Amsterdam. 
Chava, S., and M. R. Roberts, 2007, "How does Financing Impact Investment? The Role of Debt Covenants," Journal of Finance, forthcoming.

Chen, Q., I. Goldstein, and W. Jiang, 2007, "Price Informativeness and Investment Sensitivity to Stock Price," Review of Financial Studies, forthcoming.

Chirinko, R., and H. Schaller, 1996, "Bubbles, Fundamentals, and Investment: A Multiple Equation Testing Strategy," Journal of Monetary Economics 38, 47-76.

Chirinko, R., and H. Schaller, 2001, "Business Fixed Investment and 'Bubbles': The Japanese Case," American Economic Review 91, 663-680.

Chirinko, R., and H. Schaller, 2005, "Value versus Glamour: The Real Story," mimeo. Emory University.

Cooper, R., and J. Ejarque, 2003, "Financial Frictions and Investment: Requiem in $q$," Review of Economic Dynamics 6, 710-728.

Damodaran, A., 1993, "A Simple Measure of Price Adjustment Coefficients," Journal of Finance 48, 387-400.

Dierkens, N., 1991, "Information Asymmetry and Equity Issues," Journal of Financial and Quantitative Analysis 26, 181-199.

Diether, K., C. Malloy, and A. Scherbina, 2002, "Differences of Opinion and the Cross-Section of Stock Returns." Journal of Finance 57, 2113-2141.

Dow, J., I. Goldstein, and A. Guembel, 2006, "Incentives for Information Production in Markets where Prices Affect Real Investment," mimeo. University of Pennsylvania.

Dow, J., and G. Gorton, 1997, "Stock Market Efficiency and Economic Efficiency: Is There a Connection?" Journal of Finance 52, 1087-1129.

Duarte, J., and L. Young, 2007, "Why is PIN Priced?" Journal of Financial Economics, forthcoming.

Durnev, A., R. Morck and B. Yeung, 2004, "Value Enhancing Capital Budgeting and Firm-specific Stock Return Variation," Journal of Finance 59, 2004, 65-105 
Easley, D., N. Kiefer, and M. O'Hara, 1996, "Cream-Skimming or Profit-Sharing? The Curious Role of Purchased Order Flow," Journal of Finance 51, 811-833.

Erickson, T., and T. M. Whited, 2000, "Measurement Error and the Relationship between Investment and q," Journal of Political Economy 108, 1027-1057.

Erickson, T., and T. M. Whited, 2002, "Two-Step GMM Estimation of the Errors-in-Variables Model Using High-Order Moments," Econometric Theory 18, 776-799.

Erickson, T., and T. M. Whited, 2006, "On the Accuracy of Different Measures of Q," Financial Management 35, 5-33.

Fama, E., and J. MacBeth, 1973, "Risk, Return, and Equilibrium: Empirical Tests," Journal of Political Economy 81, 607-36.

Fazzari, S. M., R. G. Hubbard, and B. C. Petersen, 1988, "Financing Constraints and Corporate Investment," Brookings Papers on Economic Activity 1, 141-195.

Geary, R. C., 1942, "Inherent Relations between Random Variables." Proceedings of the Royal Irish Academy A 47, 63-76.

Gilchrist, S., C. P. Himmelberg, and G. Huberman, 2005, "Do Stock Price Bubbles Influence Corporate Investment?" Carnegie-Rochester Conference Series on Public Policy

Goyal, V., and T. Yamada, 2004, "Asset Price Shocks, Financial Constraints, and Investment: Evidence from Japan," Journal of Business, 77, 175-199.

Graham, J. R. and M. Campello, 2007, "Do Stock Prices Influence Corporate Decisions? Evidence from the Technology Bubble," mimeo. Duke University.

Hall, P., and Horowitz, J. L., 1996, "Bootstrap Critical Values for Tests Based on GeneralizedMethod-of-Moment Estimators." Econometrica 64, 891-916.

Hayashi, F., 1982, "Tobin's Marginal and Average q: A Neoclassical Interpretation," Econometrica $50,213-224$.

Hennessy, C. A., 2004, "Tobin's Q, Debt Overhang, and Investment," Journal of Finance 59, $1717-1742$. 
Hennessy, C. A., and T. M. Whited, 2007, "How Costly is External Financing? Evidence from a Structural Estimation," Journal of Finance 62, 1705-1745.

Hong, H., T. Lim, and J. Stein, 2000, "Bad News Travels Slowly: Size, Analyst Coverage, and the Profitability of Momentum Strategies," Journal of Finance 55, 265-295.

Hou, K., and T. J. Moskowitz, 2005, "Market Frictions, Price Delay, and the Cross-Section of Expected Returns," Review of Financial Studies 18, 981-1020.

Johnson, T. C., 2004, "Forecast Dispersion and the Cross Section of Expected Returns," Journal of Finance 59, 1957-1978.

Kaplan, S. N., and L. Zingales, 1997, "Do Investment-Cash Flow Sensitivities Provide Useful Measures of Financing Constraints?" Quarterly Journal of Economics 112, 169-215.

Keynes, J. M., 1936, The General Theory of Employment, Interest and Money, London, Macmillan and Co.

Klepper, S. and E. E. Leamer, 1984, "Consistent Sets of Estimates for Regressions with Errors in all Variables," Econometrica 52, 163-183.

Leahy, J. V., and T. M. Whited, 1996, "The Effect of Uncertainty on Investment: Some Stylized Facts," Journal of Money, Credit, and Banking 28, 64-83.

Luo, Y., 2005, "Do Insiders Learn from Outsiders? Evidence from Mergers and Acquisitions," Journal of Finance 60, 1951-1982.

Merton, R. C., and S. Fischer, 1984, "Macroeconomics and Finance: The Role of the Stock Market," Carnegie-Rochester Conference Series on Public Policy 21, 57-108.

Morck, R., A. Shleifer, and R. Vishny, 1990, "The Stock Market and Investment: Is the Market a Side Show?" Brookings Papers on Economic Activity 2, 157-215.

Myers, S. C., and N. S. Majluf, 1984, "Corporate Financing and Investment Decisions When Firms Have Information that Investors do not Have," Journal of Financial Economics 13, 187-221.

Panageas, S., 2005a, "The Neoclassical Theory of Investment in Speculative Markets," mimeo. University of Pennsylvania. 
Panageas, S., 2005b, "Speculation, Overpricing and Investment: Empirical Evidence," mimeo. University of Pennsylvania.

Petersen, M. A., 2005, "Estimating Standard Errors in Finance Panel Data Sets: Comparing Approaches," Review of Financial Studies, forthcoming.

Polk, C., and P. Sapienza, 2007, "The Stock Market and Corporate Investment: A Test of Catering Theory," Review of Financial Studies, forthcoming.

Rauh, J. D., 2006, "Investment and Financing Constraints: Evidence from the Funding of Corporate Pension Plans," Journal of Finance 61, 33-71.

Roll, R., 1988, “R2," Journal of Finance 43, 541-563.

Sabia, J. J., 2007a, "The Effect of Body Weight on Adolescent Academic Performance," Southern Economic Journal 73, 871-900.

Sabia, J. J., 2007b, "Early Adolescent Sex and Diminished School Attachment: Selection or Spillovers?" Southern Economic Journal 74, 239-268.

Sadka, R., and A. Scherbina, 2006, "Analyst Disagreement, Mispricing, and Liquidity," Journal of Finance, forthcoming.

Stein, J., 1996, "Rational Capital Budgeting in an Irrational World," Journal of Business 69, 429-55.

Subrahmanyam, A., and S. Titman, 1999, "The Going-Public Decision and the Development of Financial Markets," Journal of Finance 54, 1045-82.

Summers, L. H., 1981, "Taxation and Corporate Investment: A Q-Theoretic Approach", Brookings Papers on Economics Activity 1, 67-140.

Whited, T. M., and G. Wu, 2006, "Financial Constraints Risk," Review of Financial Studies 19, 531-559. 


\section{Endnotes}

1. We are grateful for helpful suggestions from an anonymous referee, Malcolm Baker, Bob Chirinko, Morris Davis, Chris Hennessy, Alexander Ljungqvist, Antonio Mello, Stavros Panageas, Jeff Pontiff, Paul Povel, Michael Roberts, Huntley Schaller, Missaka Warusawitharana, and seminar participants at Berkeley, Carleton University, Hong Kong University of Science and Technology, National University of Singapore, Singapore Management University, Stanford, Tel Aviv University, UCLA, USC, Temple, University of Wisconsin-Madison, Vanderbilt, the Minnesota-Wisconsin Corporate Finance Conference, and the 2007 AFA Meetings. We are also especially grateful to Jefferson Duarte and Wei Jiang for providing us with some of the data used in the paper.

2. This technique has been used in a number of recent papers. See Hennessy (2004), Rauh (2006), Almeida and Campello (2007), Polk and Sapienza (2007), and Sabia (2007a,b).

3. Because there may nonetheless be some cross-sectional dependence among the firms in the same industry, we also try to include two-digit industry fixed effects. The results are qualitatively similar.

4. We leave to future research attempts to exploit time-series variation in investment and Tobin's $q$ to identify managerial attention to the stock market.

5. See Chava and Roberts (2007) for a similar specification.

6. We thank Wei Jiang and Jefferson Duarte for providing us with the insider trading and the $A P I N$ data.

7. We also consider the index of financial constraints in Whited and Wu (2006) and firm age. Because these two measures of financial constraints produce almost identical results to those found using firm size, we omit them.

8. We have not used their other measure of managerial information: the abnormal return around an earnings surprise, given that it is closely related to one of our proxies for mispricing, $E S$. Insider trades are not as closely related to mispricing inasmuch as insider trades release 
information to the market. In contrast, earnings surprises happen after information has been withheld from the market and therefore represent ex ante information asymmetry.

9. This result is different from that in Erickson and Whited (2000), which finds that $\tau^{2}$ is approximately the same across size classes. We attribute this difference to our much larger sample that spans many more industries.

10. The results in Table 7 are also robust along this line, although we have omitted them for brevity. 


\section{Table 1}

\section{Summary Statistics: Firms Sorted by Finance Constraints}

\begin{tabular}{lcccc}
\hline Firms Sorted by Size & Small & Quartile 2 & Quartile 3 & Large \\
\hline Investment/Assets & 0.095 & 0.093 & 0.093 & 0.088 \\
Tobin's $q$ & 5.191 & 4.035 & 3.362 & 2.801 \\
Market-to-Book & 2.253 & 1.745 & 1.652 & 1.614 \\
Cash Flow/Assets & 0.019 & 0.078 & 0.093 & 0.101 \\
Total Assets & 17.511 & 71.686 & 256.256 & 4595.245 \\
Leverage & 0.131 & 0.160 & 0.201 & 0.224 \\
Bond Rating & 0.040 & 0.101 & 0.216 & 0.623 \\
Equity Issuance & 0.101 & 0.059 & 0.034 & 0.016 \\
\hline Firms Sorted by Kaplan-Zingales Index & & & & \\
& Unconstrained & Quartile 2 & Quartile 3 & Constrained \\
\hline Investment/Assets & 0.091 & 0.092 & 0.090 & 0.096 \\
Tobin's $q$ & 3.492 & 5.585 & 3.522 & 2.789 \\
Market-to-Book & 2.000 & 2.014 & 1.675 & 1.575 \\
Cash Flow/Assets & 0.130 & 0.097 & 0.045 & 0.020 \\
Total Assets & 1755.389 & 984.257 & 1336.665 & 883.426 \\
Leverage & 0.095 & 0.074 & 0.159 & 0.387 \\
Bond Rating & 0.349 & 0.186 & 0.218 & 0.226 \\
Equity Issuance & 0.033 & 0.069 & 0.062 & 0.047 \\
\hline
\end{tabular}

Calculations are based on a sample of unregulated and nonfinancial firms from the 2005 Compustat annual industrial files. The sample period is from 1990 to 2004. The denominator of Tobin's $q$ is the gross capital stock. The numerator is the sum of the market value of common equity and the book value of debt minus the book value of inventories. The denominator of the market-to-book ratio is the book value of total assets. The numerator is the book value of total assets minus the book value of equity minus balance-sheet deferred taxes plus the market value of equity. Equity Issuance is the size of the equity issue as a fraction of total book assets, conditional on actual issuance. Bond Rating is an indicator that takes the value of one if the firm has a bond rating. The total assets figures are in millions of 1997 dollars. Leverage is defined as the ratio of total long-term debt to total assets. The KZ index is an index of financial constraints from Kaplan and Zingales (1997), in which higher numbers indicate a greater likelihood of facing external finance constraints. 
Table 2

Summary Statistics: Firms Sorted by Measures of Information

\begin{tabular}{|c|c|c|c|c|}
\hline & Uninformative & Quartile 2 & Quartile 3 & Informative \\
\hline \multicolumn{5}{|l|}{ Firms Sorted by $\Psi$} \\
\hline Investment/Assets & 0.083 & 0.079 & 0.077 & 0.087 \\
\hline Tobin's $q$ & 3.450 & 4.266 & 4.365 & 3.893 \\
\hline Market-to-Book & 1.768 & 1.897 & 1.932 & 1.870 \\
\hline Cash Flow/Assets & 0.092 & 0.065 & 0.056 & 0.063 \\
\hline Total Assets & 3432.810 & 1478.808 & 1181.869 & 672.708 \\
\hline Leverage & 0.184 & 0.177 & 0.177 & 0.179 \\
\hline Bond Rating & 0.425 & 0.256 & 0.207 & 0.156 \\
\hline Equity Issuance & 0.019 & 0.036 & 0.045 & 0.047 \\
\hline \multicolumn{5}{|c|}{ Firms Sorted by $A P I N$} \\
\hline Investment/Assets & 0.076 & 0.086 & 0.087 & 0.080 \\
\hline Tobin's $q$ & 3.666 & 3.113 & 2.704 & 2.091 \\
\hline Market-to-Book & 1.994 & 1.742 & 1.621 & 1.410 \\
\hline Cash Flow/Assets & 0.103 & 0.098 & 0.091 & 0.081 \\
\hline Total Assets & 6670.251 & 2072.203 & 990.108 & 439.181 \\
\hline Leverage & 0.215 & 0.223 & 0.230 & 0.226 \\
\hline Bond Rating & 0.667 & 0.483 & 0.354 & 0.189 \\
\hline Equity Issuance & 0.016 & 0.018 & 0.022 & 0.016 \\
\hline \multicolumn{5}{|c|}{ Firms Sorted by \# Analysts } \\
\hline Investment/Assets & 0.068 & 0.081 & 0.095 & 0.103 \\
\hline Tobin's $q$ & 3.345 & 4.013 & 5.097 & 5.078 \\
\hline Market-to-Book & 1.641 & 1.778 & 2.042 & 2.244 \\
\hline Cash Flow/Assets & 0.017 & 0.060 & 0.101 & 0.125 \\
\hline Total Assets & 567.608 & 1017.044 & 1105.819 & 4487.384 \\
\hline Leverage & 0.176 & 0.169 & 0.176 & 0.180 \\
\hline Bond Rating & 0.086 & 0.141 & 0.291 & 0.565 \\
\hline Equity Issuance & 0.046 & 0.049 & 0.049 & 0.027 \\
\hline \multicolumn{5}{|c|}{ Firms Sorted by INSIDE } \\
\hline Investment/Assets & 0.072 & 0.077 & 0.074 & 0.081 \\
\hline Tobin's $q$ & 8.112 & 5.541 & 4.392 & 3.265 \\
\hline Market-to-Book & 2.770 & 2.173 & 1.868 & 1.637 \\
\hline Cash Flow/Assets & 0.055 & 0.074 & 0.078 & 0.096 \\
\hline Total Assets & 3761.140 & 2140.377 & 1079.604 & 686.157 \\
\hline Leverage & 0.129 & 0.153 & 0.168 & 0.203 \\
\hline Bond Rating & 0.355 & 0.290 & 0.287 & 0.270 \\
\hline Equity Issuance & 0.061 & 0.042 & 0.030 & 0.020 \\
\hline
\end{tabular}


Calculations are based on a sample of unregulated and nonfinancial firms from the 2005 Compustat annual industrial files. The sample period is from 1990 to 2004. The denominator of Tobin's $q$ is the gross capital stock. The numerator is the sum of the market value of common equity and the book value of debt minus the book value of inventories. The denominator of the market-to-book ratio is the book value of total assets. The numerator is the book value of total assets minus the book value of equity minus balance-sheet deferred taxes plus the market value of equity. Equity Issuance is the size of the equity issue as a fraction of total book assets, conditional on actual issuance. Bond Rating is an indicator that takes the value of one if the firm has a bond rating. The total assets figures are in millions of 1997 dollars. Leverage is defined as the ratio of total long-term debt to total assets. $\Psi$ is a measure of idiosyncratic volatility from Durnev, Morck, and Yeung (2004). APIN is a measure of the probability of informed trading from Duarte and Young (2007). INSIDE is the fraction of trades made by insiders in a given year, divided by the total number of trades. 


\section{Table 3}

Summary Statistics: Firms Sorted by Measures of Mispricing

\begin{tabular}{|c|c|c|c|c|}
\hline & Low Mispricing & Quartile 2 & Quartile 3 & High Mispricing \\
\hline \multicolumn{5}{|c|}{ Firms Sorted by $S D E V$} \\
\hline Investment/Assets & 0.098 & 0.085 & 0.084 & 0.061 \\
\hline Tobin's $q$ & 2.178 & 2.869 & 3.464 & 7.733 \\
\hline Market-to-Book & 1.609 & 1.637 & 1.813 & 2.428 \\
\hline Cash Flow/Assets & 0.109 & 0.054 & 0.099 & 0.016 \\
\hline Total Assets & 3343.385 & 1275.307 & 1999.133 & 817.626 \\
\hline Leverage & 0.223 & 0.205 & 0.175 & 0.116 \\
\hline Bond Rating & 0.454 & 0.181 & 0.310 & 0.132 \\
\hline Equity Issuance & 0.017 & 0.039 & 0.026 & 0.067 \\
\hline \multicolumn{5}{|l|}{ Firms Sorted by $E S$} \\
\hline Investment/Assets & 0.106 & 0.085 & 0.096 & 0.068 \\
\hline Tobin's $q$ & 2.145 & 3.439 & 3.497 & 8.778 \\
\hline Market-to-Book & 1.561 & 1.722 & 1.880 & 2.638 \\
\hline Cash Flow/Assets & 0.112 & 0.104 & 0.101 & 0.018 \\
\hline Total Assets & 2814.553 & 2418.374 & 1613.944 & 641.754 \\
\hline Leverage & 0.219 & 0.190 & 0.179 & 0.111 \\
\hline Bond Rating & 0.404 & 0.342 & 0.286 & 0.111 \\
\hline Equity Issuance & 0.021 & 0.031 & 0.033 & 0.083 \\
\hline \multicolumn{5}{|c|}{ Firms Sorted by $A B R E T$} \\
\hline Investment/Assets & 0.085 & 0.083 & 0.087 & 0.090 \\
\hline Tobin's $q$ & 3.284 & 3.658 & 3.813 & 6.419 \\
\hline Market-to-Book & 1.738 & 1.744 & 1.857 & 2.310 \\
\hline Cash Flow/Assets & 0.100 & 0.069 & 0.092 & 0.038 \\
\hline Total Assets & 2365.110 & 1148.370 & 2434.530 & 983.509 \\
\hline Leverage & 0.181 & 0.176 & 0.179 & 0.164 \\
\hline Bond Rating & 0.336 & 0.206 & 0.324 & 0.186 \\
\hline Equity Issuance & 0.025 & 0.044 & 0.030 & 0.065 \\
\hline
\end{tabular}


Calculations are based on a sample of unregulated and nonfinancial firms from the 2005 Compustat annual industrial files. The sample period is from 1990 to 2004. The denominator of Tobin's $q$ is the gross capital stock. The numerator is the sum of the market value of common equity and the book value of debt minus the book value of inventories. The denominator of the market-to-book ratio is the book value of total assets. The numerator is the book value of total assets minus the book value of equity minus balance-sheet deferred taxes plus the market value of equity. Equity Issuance is the size of the equity issue as a fraction of total book assets, conditional on actual issuance. Bond Rating is an indicator that takes the value of one if the firm has a bond rating. The total assets figures are in millions of 1997 dollars. Leverage is defined as the ratio of total long-term debt to total assets. $S D E V$ is the standard deviation of analysts' earning estimates, rescaled as a fraction of the capital stock. ES is the consensus analyst earnings estimate minus actual earnings, rescaled as a fraction of the capital stock. $A B R E T$ is the average one-year cumulative abnormal return. 


\section{Table 4}

\section{Informativeness-Sorted Investment Regressions}

\begin{tabular}{lccc}
\hline & OLS & \multicolumn{2}{c}{ GMM } \\
& $q$ & & $\tau^{2}$ \\
\hline$\Psi$ & & & \\
\hline Uninformative & $0.017^{* \dagger}$ & $0.046^{* \dagger}$ & $0.459^{* \dagger}$ \\
Quartile 2 & $(0.003)$ & $(0.011)$ & $(0.042)$ \\
& $0.026^{* \dagger}$ & $0.044^{* \dagger}$ & $0.506^{* \dagger}$ \\
Quartile 3 & $(0.002)$ & $(0.008)$ & $(0.028)$ \\
& $0.027^{* \dagger}$ & $0.051^{* \dagger}$ & $0.525^{* \dagger}$ \\
Informative & $(0.003)$ & $(0.013)$ & $(0.038)$ \\
& $0.032^{* \dagger}$ & $0.053^{* \dagger}$ & $0.576^{* \dagger}$ \\
\hline APIN & $(0.002)$ & $(0.011)$ & $(0.053)$ \\
\hline Uninformative & 0.010 & & \\
Quartile 2 & $(0.007)$ & $0.042^{* \dagger}$ & $0.289^{* \dagger}$ \\
& $0.011^{* \dagger}$ & $(0.008)$ & $(0.067)$ \\
Quartile 3 & $(0.003)$ & $0.049^{* \dagger}$ & $0.382^{* \dagger}$ \\
& $0.016^{* \dagger}$ & $(0.017)$ & $(0.097)$ \\
Informative & $(0.004)$ & $0.053^{* \dagger}$ & $0.466^{* \dagger}$ \\
& $0.021^{* \dagger}$ & $(0.033)$ & $(0.077)$ \\
& $(0.004)$ & $0.057^{* \dagger}$ & $0.537^{* \dagger}$ \\
& & $(0.023)$ & $(0.052)$ \\
\hline
\end{tabular}

Calculations are based on a sample of unregulated and nonfinancial firms from the 2005 Compustat annual industrial files. The sample period is from 1990 to 2004. $\tau^{2}$ is the ratio of signal to the sum of signal and noise for Tobin's $q . \Psi$ is a measure of idiosyncratic volatility from Durnev, Morck, and Yeung (2004). APIN is a measure of the probability of informed trading from Duarte and Young (2007). Fama-MacBeth (1973) standard errors are in parentheses under the parameter estimates. An asterisk indicates that the t-statistic associated with the standard error exceeds its $5 \%$ bootstrapped critical value. A dagger indicates that over half of the t-statistics corresponding to the yearly estimates exceed their $5 \%$ bootstrapped critical values. 


\section{Table 5}

\section{Investment Regressions Sorted by the Type of Information}

\begin{tabular}{lcccccc}
\hline & \multicolumn{3}{c}{ High INSIDE } & \multicolumn{3}{c}{ Low INSIDE } \\
& OLS & \multicolumn{2}{c}{ GMM } & OLS & \multicolumn{2}{c}{ GMM } \\
& $q$ & $q$ & $\tau^{2}$ & $q$ & $q$ & $\tau^{2}$ \\
\hline High APIN & $0.013^{* \dagger}$ & $0.026^{* \dagger}$ & $0.510^{* \dagger}$ & $0.019^{* \dagger}$ & 0.044 & $0.652^{* \dagger}$ \\
& $(0.005)$ & $(0.009)$ & $(0.077)$ & $(0.002)$ & $(0.010)$ & $(0.090)$ \\
Low APIN & $0.003^{* \dagger}$ & 0.014 & $0.345^{* \dagger}$ & $0.010^{* \dagger}$ & $0.021^{\dagger}$ & $0.447^{* \dagger}$ \\
& $(0.001)$ & $(0.002)$ & $(0.054)$ & $(0.003)$ & $(0.007)$ & $(0.077)$ \\
\hline High $\Psi$ & $0.020^{* \dagger}$ & $0.053^{\dagger}$ & $0.584^{* \dagger}$ & $0.024^{* \dagger}$ & $0.045^{* \dagger}$ & $0.645^{* \dagger}$ \\
& $(0.003)$ & $(0.027)$ & $(0.085)$ & $(0.002)$ & $(0.006)$ & $(0.041)$ \\
Low $\Psi$ & $0.019^{* \dagger}$ & $0.034^{* \dagger}$ & $0.354^{* \dagger}$ & $0.015^{* \dagger}$ & $0.031^{* \dagger}$ & $0.527^{* \dagger}$ \\
& $(0.004)$ & $(0.006)$ & $(0.133)$ & $(0.003)$ & $(0.010)$ & $(0.039)$ \\
\hline
\end{tabular}

\begin{tabular}{lcccccc} 
& \multicolumn{3}{c}{ High NANAL } & \multicolumn{3}{c}{ Low NANAL } \\
& OLS & \multicolumn{2}{c}{ GMM } & OLS & \multicolumn{2}{c}{ GMM } \\
& $q$ & $q$ & $\tau^{2}$ & $q$ & $q$ & $\tau^{2}$ \\
\hline High APIN & $0.016^{* \dagger}$ & $0.029^{* \dagger}$ & $0.693^{* \dagger}$ & $0.027^{* \dagger}$ & $0.047^{* \dagger}$ & $0.463^{* \dagger}$ \\
& $(0.003)$ & $(0.006)$ & $(0.057)$ & $(0.005)$ & $(0.015)$ & $(0.067)$ \\
Low APIN & $0.008^{* \dagger}$ & $0.019^{* \dagger}$ & $0.542^{* \dagger}$ & $0.022^{* \dagger}$ & $0.068^{* \dagger}$ & $0.253^{* \dagger}$ \\
& $(0.001)$ & $(0.007)$ & $(0.037)$ & $(0.006)$ & $(0.020)$ & $(0.073)$ \\
\hline High $\Psi$ & $0.030^{* \dagger}$ & $0.055^{* \dagger}$ & $0.734^{* \dagger}$ & $0.031^{* \dagger}$ & $0.066^{* \dagger}$ & $0.453^{* \dagger}$ \\
& $(0.003)$ & $(0.010)$ & $(0.095)$ & $(0.004)$ & $(0.011)$ & $(0.044)$ \\
Low $\Psi$ & $0.020^{* \dagger}$ & $0.043^{* \dagger}$ & $0.529^{* \dagger}$ & $0.020^{* \dagger}$ & $0.054^{* \dagger}$ & $0.352^{* \dagger}$ \\
& $(0.002)$ & $(0.012)$ & $(0.041)$ & $(0.003)$ & $(0.010)$ & $(0.081)$ \\
\hline
\end{tabular}

Calculations are based on a sample of unregulated and nonfinancial firms from the 2005 Compustat annual industrial files. The sample period is from 1990 to 2004. $\tau^{2}$ is the ratio of signal to the sum of signal and noise for Tobin's $q . \Psi$ is a measure of idiosyncratic volatility from Durnev, Morck, and Yeung (2004). APIN is a measure of the probability of informed trading from Duarte and Young (2007). INSIDE is the fraction of trades made by insiders in a given year, divided by the total number of trades. Fama-MacBeth (1973) standard errors are in parentheses under the parameter estimates. An asterisk indicates that the t-statistic associated with the standard error exceeds its $5 \%$ bootstrapped critical value. A dagger indicates that over half of the t-statistics corresponding to the yearly estimates exceed their $5 \%$ bootstrapped critical values. 


\section{Table 6}

\section{Investment Regressions Sorted by Measures of Finance Constraints}

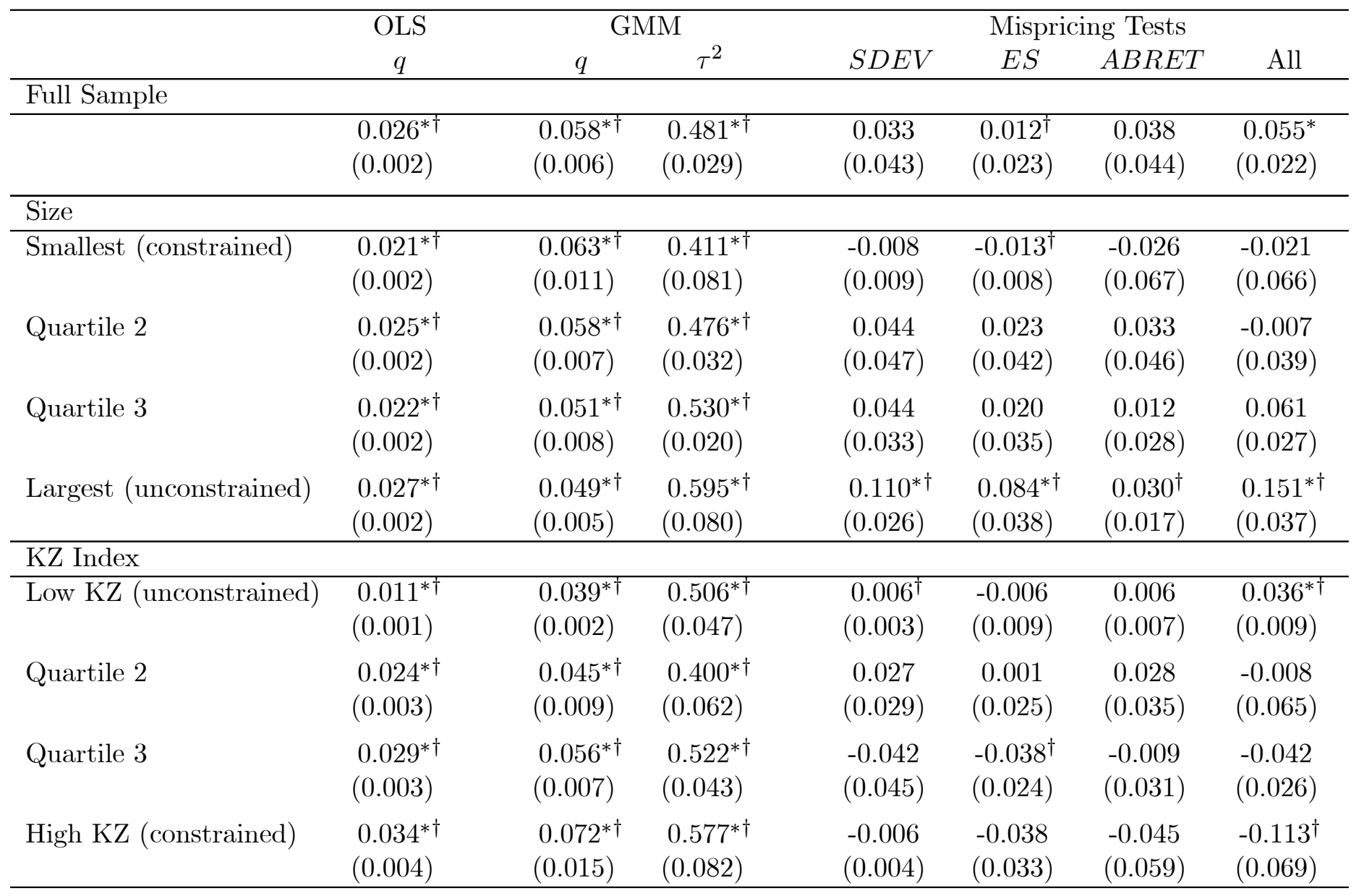

Calculations are based on a sample of unregulated and nonfinancial firms from the 2005 Compustat annual industrial files. The sample period is from 1990 to 2004. Size is calculated as total book assets, and the first quartile contains the smallest firms. The KZ index is an index of financial constraints from Kaplan and Zingales (1997), in which higher numbers indicate a greater likelihood of facing external finance constraints. $\tau^{2}$ is the ratio of signal to the sum of signal and noise for Tobin's $q$. $S D E V, E S$, and $A B R E T$ are proxies for mispricing. $S D E V$ is the standard deviation of analysts' earning estimates, rescaled as a fraction of the capital stock. ES is the consensus analyst earnings estimate minus actual earnings, rescaled as a fraction of the capital stock. $A B R E T$ is the average one-year cumulative abnormal return. A mispricing test greater than zero indicates that mispricing does not affect investment, and a test less than zero indicates that mispricing does. Fama-MacBeth (1973) standard errors are in parentheses under the parameter estimates. An asterisk indicates that the t-statistic associated with the standard error exceeds its $5 \%$ bootstrapped critical value. A dagger indicates that over half of the t-statistics corresponding to the yearly estimates exceed their $5 \%$ bootstrapped critical values. 


\section{Table 6}

\section{Mispricing-Sorted Investment Regressions}

\begin{tabular}{|c|c|c|c|c|c|c|c|}
\hline \multirow{3}{*}{$S D E V$} & \multirow{2}{*}{$\begin{array}{c}\text { OLS } \\
q\end{array}$} & \multicolumn{2}{|c|}{ GMM } & \multicolumn{4}{|c|}{ Mispricing Tests } \\
\hline & & $q$ & $\tau^{2}$ & $S D E V$ & $E S$ & $A B R E T$ & All \\
\hline & & & & & & & \\
\hline Low Overpricing & $\begin{array}{c}0.025^{* \dagger} \\
(0.002)\end{array}$ & $\begin{array}{c}0.055^{* \dagger} \\
(0.014)\end{array}$ & $\begin{array}{l}0.508^{* \dagger} \\
(0.050)\end{array}$ & $\begin{array}{c}0.025 \\
(0.070)\end{array}$ & $\begin{array}{c}-0.006 \\
(0.028)\end{array}$ & $\begin{array}{c}0.036 \\
(0.056)\end{array}$ & $\begin{array}{l}-0.023 \\
(0.034)\end{array}$ \\
\hline Quartile 2 & $\begin{array}{c}0.022^{* \dagger} \\
(0.003)\end{array}$ & $\begin{array}{c}0.033^{* \dagger} \\
(0.005)\end{array}$ & $\begin{array}{l}0.488^{* \dagger} \\
(0.054)\end{array}$ & $\begin{array}{l}-0.037 \\
(0.038)\end{array}$ & $\begin{array}{c}0.006 \\
(0.018)\end{array}$ & $\begin{array}{l}-0.065 \\
(0.109)\end{array}$ & $\begin{array}{c}0.032 \\
(0.013)\end{array}$ \\
\hline Quartile 3 & $\begin{array}{c}0.024^{* \dagger} \\
(0.003)\end{array}$ & $\begin{array}{c}0.047^{* \dagger} \\
(0.013)\end{array}$ & $\begin{array}{l}0.496^{* \dagger} \\
(0.083)\end{array}$ & $\begin{array}{c}0.011 \\
(0.011)\end{array}$ & $\begin{array}{c}0.007 \\
(0.015)\end{array}$ & $\begin{array}{c}0.077^{\dagger} \\
(0.049)\end{array}$ & $\begin{array}{c}0.059^{\dagger} \\
(0.023)\end{array}$ \\
\hline High Overpricing & $\begin{array}{l}0.024^{* \dagger} \\
(0.002)\end{array}$ & $\begin{array}{c}0.058^{* \dagger} \\
(0.014)\end{array}$ & $\begin{array}{c}0.446^{* \dagger} \\
(0.043) \\
\end{array}$ & $\begin{array}{r}0.034^{\dagger} \\
(0.017) \\
\end{array}$ & $\begin{array}{c}0.011 \\
(0.008) \\
\end{array}$ & $\begin{array}{c}0.060^{* \dagger} \\
(0.017) \\
\end{array}$ & $\begin{array}{c}0.065^{* \dagger} \\
(0.031)\end{array}$ \\
\hline$E S$ & & & & & & & \\
\hline Underpricing & $\begin{array}{c}0.023^{* \dagger} \\
(0.002)\end{array}$ & $\begin{array}{c}0.056^{* \dagger} \\
(0.007)\end{array}$ & $\begin{array}{l}0.512^{* \dagger} \\
(0.064)\end{array}$ & $\begin{array}{l}-0.019 \\
(0.018)\end{array}$ & $\begin{array}{l}-0.047 \\
(0.040)\end{array}$ & $\begin{array}{l}-0.044^{\dagger} \\
(0.023)\end{array}$ & $\begin{array}{l}-0.056^{\dagger} \\
(0.030)\end{array}$ \\
\hline Quartile 2 & $\begin{array}{l}0.026^{* \dagger} \\
(0.002)\end{array}$ & $\begin{array}{c}0.069^{* \dagger} \\
(0.010)\end{array}$ & $\begin{array}{c}0.486^{* \dagger} \\
(0.040)\end{array}$ & $\begin{array}{c}0.013 \\
(0.008)\end{array}$ & $\begin{array}{l}-0.010 \\
(0.024)\end{array}$ & $\begin{array}{c}0.038 \\
(0.048)\end{array}$ & $\begin{array}{c}0.039 \\
(0.025)\end{array}$ \\
\hline Quartile 3 & $\begin{array}{c}0.022^{* \dagger} \\
(0.003)\end{array}$ & $\begin{array}{l}0.048^{* \dagger} \\
(0.016)\end{array}$ & $\begin{array}{l}0.627^{* \dagger} \\
(0.035)\end{array}$ & $\begin{array}{c}0.018 \\
(0.012)\end{array}$ & $\begin{array}{c}0.073 \\
(0.153)\end{array}$ & $\begin{array}{c}0.027 \\
(0.039)\end{array}$ & $\begin{array}{c}0.014 \\
(0.017)\end{array}$ \\
\hline Overpricing & $\begin{array}{l}0.024^{* \dagger} \\
(0.004)\end{array}$ & $\begin{array}{l}0.058^{* \dagger} \\
(0.010)\end{array}$ & $\begin{array}{l}0.355^{* \dagger} \\
(0.054)\end{array}$ & $\begin{array}{c}0.089^{* \dagger} \\
(0.035)\end{array}$ & $\begin{array}{c}0.050 \\
(0.044)\end{array}$ & $\begin{array}{c}0.012 \\
(0.057)\end{array}$ & $\begin{array}{l}0.087^{* \dagger} \\
(0.030)\end{array}$ \\
\hline$A B R E T$ & & & & & & & \\
\hline Underpricing & $\begin{array}{l}0.023^{* \dagger} \\
(0.003)\end{array}$ & $\begin{array}{l}0.045^{* \dagger} \\
(0.006)\end{array}$ & $\begin{array}{l}0.512^{* \dagger} \\
(0.065)\end{array}$ & $\begin{array}{l}-0.020 \\
(0.018)\end{array}$ & $\begin{array}{l}-0.045 \\
(0.035)\end{array}$ & $\begin{array}{l}-0.022 \\
(0.021)\end{array}$ & $\begin{array}{l}-0.042^{\dagger} \\
(0.022)\end{array}$ \\
\hline Quartile 2 & $\begin{array}{c}0.025^{* \dagger} \\
(0.003)\end{array}$ & $\begin{array}{c}0.050^{* \dagger} \\
(0.012)\end{array}$ & $\begin{array}{l}0.508^{* \dagger} \\
(0.041)\end{array}$ & $\begin{array}{c}0.022 \\
(0.013)\end{array}$ & $\begin{array}{c}-0.023 \\
(0.017)\end{array}$ & $\begin{array}{l}-0.038 \\
(0.032)\end{array}$ & $\begin{array}{l}-0.018 \\
(0.037)\end{array}$ \\
\hline Quartile 3 & $\begin{array}{l}0.024^{* \dagger} \\
(0.001)\end{array}$ & $\begin{array}{l}0.044^{* \dagger} \\
(0.003)\end{array}$ & $\begin{array}{l}0.595^{* \dagger} \\
(0.080)\end{array}$ & $\begin{array}{l}-0.004 \\
(0.023)\end{array}$ & $\begin{array}{c}0.053 \\
(0.030)\end{array}$ & $\begin{array}{c}0.027 \\
(0.021)\end{array}$ & $\begin{array}{c}0.080^{\dagger} \\
(0.048)\end{array}$ \\
\hline Overpricing & $\begin{array}{l}0.024^{* \dagger} \\
(0.002)\end{array}$ & $\begin{array}{l}0.039^{* \dagger} \\
(0.004)\end{array}$ & $\begin{array}{l}0.458^{* \dagger} \\
(0.046)\end{array}$ & $\begin{array}{l}0.146^{* \dagger} \\
(0.055)\end{array}$ & $\begin{array}{c}0.072 \\
(0.053)\end{array}$ & $\begin{array}{l}0.078^{* \dagger} \\
(0.027)\end{array}$ & $\begin{array}{l}0.166^{* \dagger} \\
(0.070)\end{array}$ \\
\hline
\end{tabular}


Calculations are based on a sample of unregulated and nonfinancial firms from the 2005 Compustat annual industrial files. The sample period is from 1990 to $2004 . \tau^{2}$ is the ratio of signal to the sum of signal and noise for Tobin's q. SDEV, ES, and ABRET are proxies for mispricing. SDEV is the standard deviation of analysts' earning estimates, rescaled as a fraction of the capital stock. ES is the consensus analyst earnings estimate minus actual earnings, rescaled as a fraction of the capital stock. ABRET is the average one-year cumulative abnormal return. A mispricing test greater than zero indicates that mispricing does not affect investment, and a test less than zero indicates that mispricing does. Fama-MacBeth (1973) standard errors are in parentheses under the parameter estimates. An asterisk indicates that the t-statistic associated with the standard error exceeds its $5 \%$ bootstrapped critical value. A dagger indicates that over half of the t-statistics corresponding to the yearly estimates exceed their $5 \%$ bootstrapped critical values. 


\section{Table 7}

\section{Monte Carlo Performance of GMM and OLS Estimators}

\begin{tabular}{lcccc}
\hline & OLS & GMM3 & GMM4 & GMM5 \\
\hline$E(\hat{\beta})$ & 0.013 & 0.038 & 0.039 & 0.036 \\
$\operatorname{MAD}(\hat{\beta})$ & 0.027 & 0.003 & 0.003 & 0.005 \\
$\mathrm{P}(|\hat{\beta}-\beta| \leq 0.2 \beta)$ & 0.000 & 0.960 & 0.975 & 0.864 \\
$E\left(\hat{\tau}^{2}\right)$ & - & 0.456 & 0.416 & 0.453 \\
$\operatorname{MAD}\left(\hat{\tau}^{2}\right)$ & - & 0.053 & 0.044 & 0.049 \\
$\mathrm{P}\left(\left|\hat{\tau}^{2}-\tau^{2}\right| \leq 0.2 \tau^{2}\right)$ & - & 0.881 & 0.933 & 0.908 \\
\hline
\end{tabular}

Indicated expectations and probabilities are estimates based on 10,000 Monte Carlo samples of size 336 . The samples are generated by

$$
\begin{aligned}
y_{i} & =\chi_{i} \beta+u_{i} \\
x_{i} & =\gamma+\chi_{i}+\varepsilon_{i},
\end{aligned}
$$

in which $\chi_{i}$ is distributed as a normal variable raised to the fourth power, and $\varepsilon_{i}$ and $u_{i}$ are chi-squared variables with one degree of freedom. GMMn denotes the GMM estimator based on moments up to order $M=n$. OLS denotes estimates obtained by regressing $y_{i}$ on $x_{i}$.

True Values: $\beta=0.04, \tau^{2}=0.420$. 


\section{Figure 1}

\section{Aggregate Investment and the Stock Market}

This figure plots aggregate U.S. gross fixed investment and the S\&P 500 market index. Both series are expressed in logs and rescaled to equal 1 in 1980. 


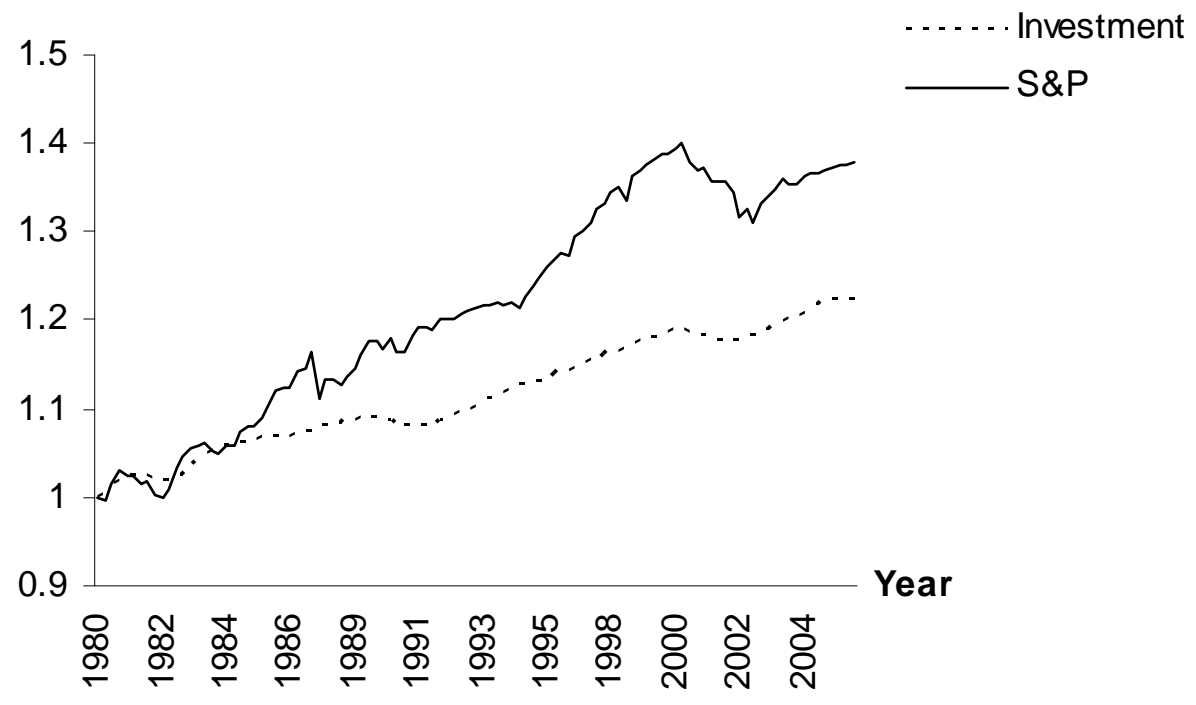




\section{Figure 2}

\section{Decomposition of the Variance of Tobin's $q$}

The distance between points $a$ and $c$ represents the variance of Tobin's $q$. The distance between points $a$ and $b$ represents the component that is relevant for investment, and the distance between points $b$ and $c$ represents the component that irrelevant for investment. Panel A represents a typical decomposition. Panels B and C represent decompositions in which variation in a proxy for nonfundamentals has been regressed out of Tobin's $q$. In Panel $\mathrm{B}$ this variation matters for investment, and in Panel $\mathrm{C}$ it does not. 
Panel A: Baseline

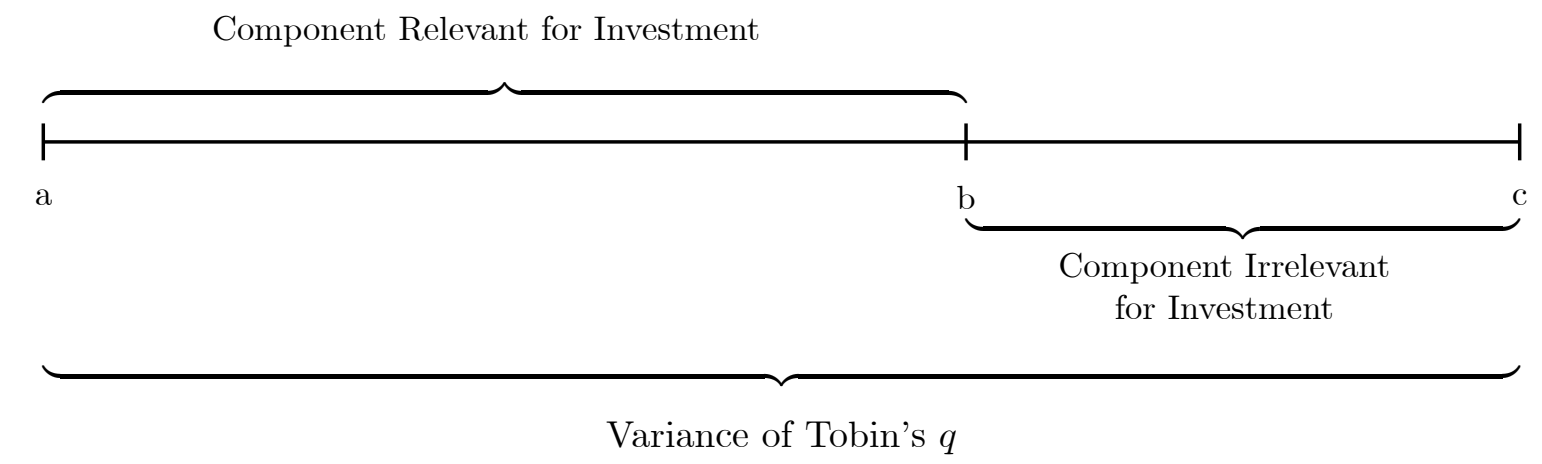

Panel B: Nonfundamentals Matter

Component Relevant for Investment

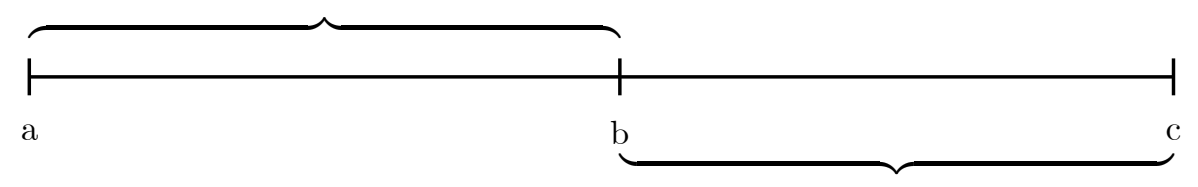

Component Irrelevant

for Investment

\section{Variance of Tobin's $q$}

Panel C: Nonfundamentals do not Matter

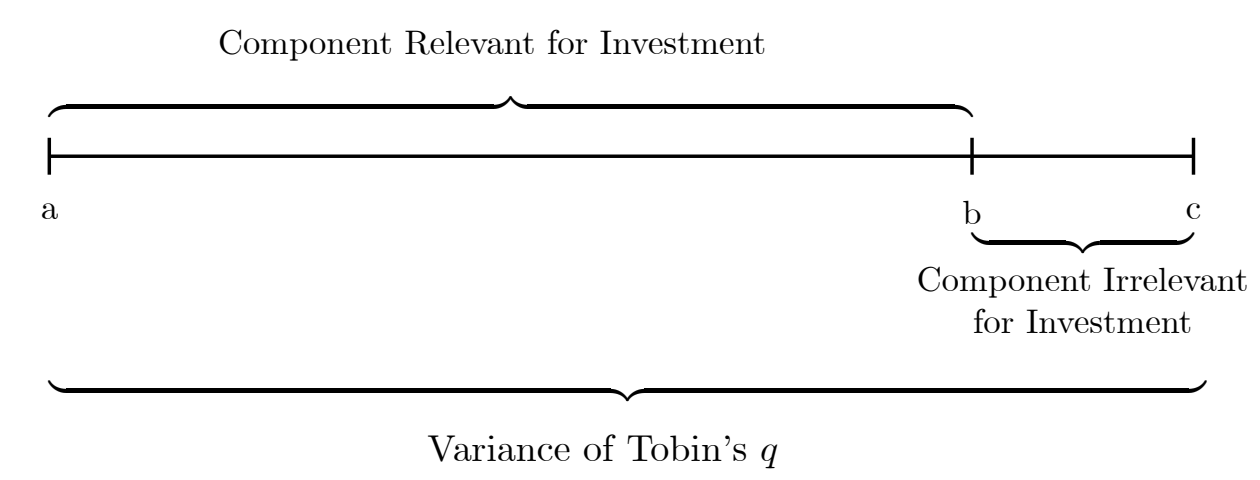




\section{Figure 3}

\section{Investment Regressions with Different Measures of $q$ Sorted by Information Measures}

Calculations are based on a sample of unregulated and nonfinancial firms from the annual 2005 COMPUSTAT industrial files. Estimation is done by OLS and the GMM4 estimator in Erickson and Whited (2002). The sample period is from 1990 to 2004 . The horizontal axis respresents sub-samples stratified by the $\Psi$, which is a measure of idiosyncratic risk. APIN is a measure of the probability of informed trading from Duarte and Young (2007). "capex-mtb" refers to estimates from a regression of the ratio of capital expenditures to assets on the market-tobook ratio. "(capex $+\mathrm{R} \& \mathrm{D})-\mathrm{mtb}$ " refers to estimates from a similar regression in which capital expenditures is replaced by the sum of capital expenditures and R\&D. "capex-macro $q$ " refers to estimates from a regression of the ratio of capital expenditures to the capital stock on macro $q$. The denominator of macro $q$ is the gross capital stock. The numerator is the sum of the market value of common equity and the book value of debt minus the book value of inventories. The denominator of the market-to-book ratio is the book value of total assets. The numerator is the book value of total assets minus the book value of equity minus balance-sheet deferred taxes plus the market value of equity. $\tau^{2}$ is the ratio of signal to the sum of signal and noise for an observable $q$ proxy. 
OLS Estimates of Investment-q Sensitivity

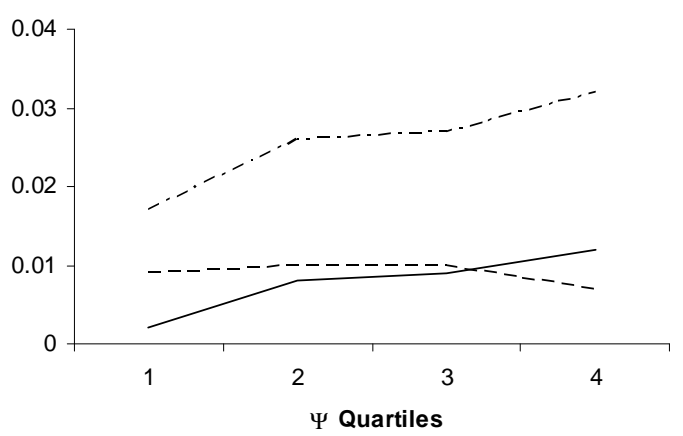

GMM Estimates of Investment-q Sensitivity

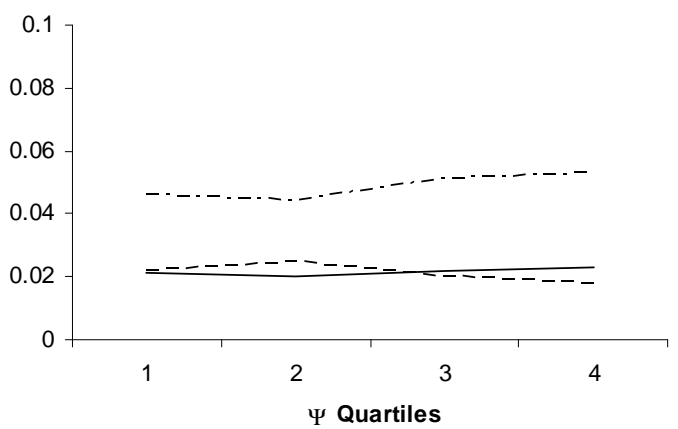

GMM Estimates of $\tau^{2}$

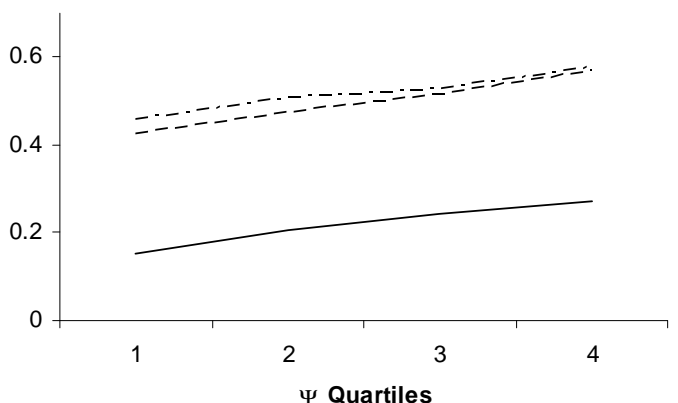

OLS Estimates of Investment-q Sensitivity

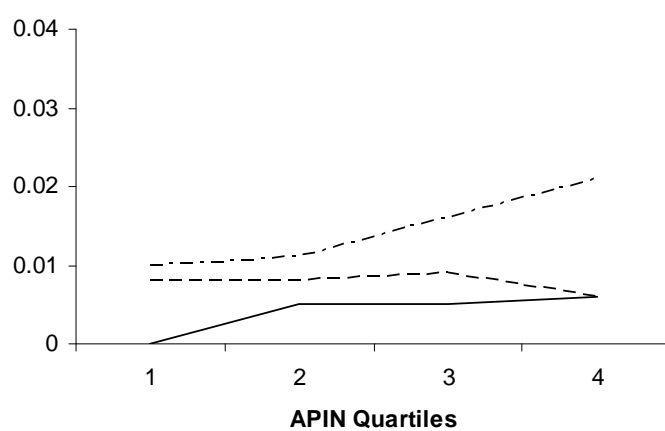

GMM Estimates of Investment- $q$ Sensitivity

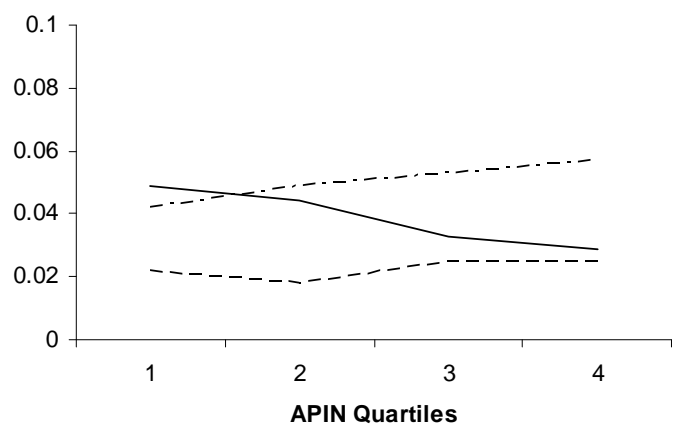

GMM Estimates of $\tau^{2}$
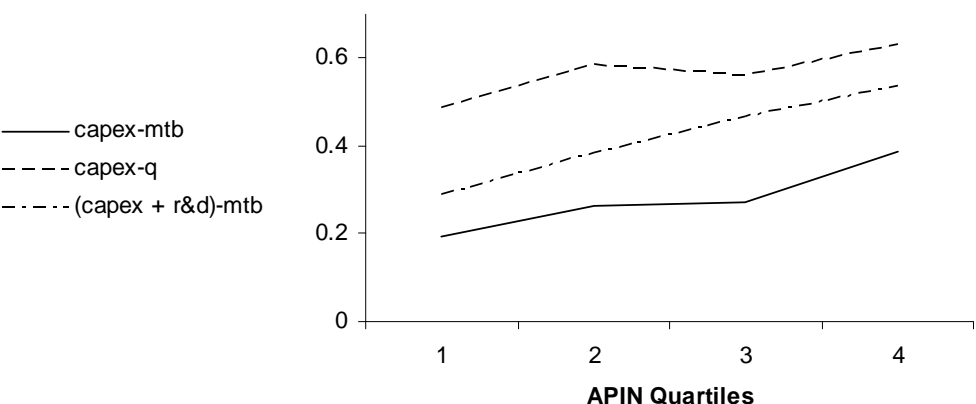

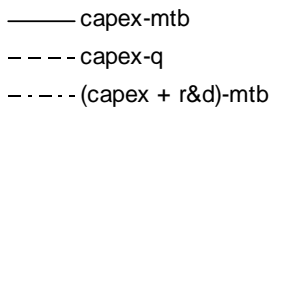
- capex-mtb
--- capex-q
--- - (capex $+r \& d)-m t b$ 


\section{Figure 4}

\section{Investment Regressions with Different Measures of $q$ Sorted by Financial Constraints Measures}

Calculations are based on a sample of unregulated and nonfinancial firms from the annual 2005 COMPUSTAT industrial files. Estimation is done by OLS and the GMM4 estimator in Erickson and Whited (2002). The sample period is from 1990 to 2004 . The horizontal axis respresents sub-samples stratified by total book assets. "capexmtb" refers to estimates from a regression of the ratio of capital expenditures to assets on the market-to-book ratio. "(capex $+\mathrm{R} \& D)-m$ tb" refers to estimates from a similar regression in which capital expenditures is replaced by the sum of capital expenditures and R\&D. "capex-macro $q$ " refers to estimates from a regression of the ratio of capital expenditures to the capital stock on macro $q$. The denominator of macro $q$ is the gross capital stock. The numerator is the sum of the market value of common equity and the book value of debt minus the book value of inventories. The denominator of the market-to-book ratio is the book value of total assets. The numerator is the book value of total assets minus the book value of equity minus balance-sheet deferred taxes plus the market value of equity. Mispricing tests are estimates of $\tau^{2}-\tau_{m}^{2} \cdot \tau^{2}-\tau_{m}^{2}>0$ implies that mispricing is relevant for investment, and $\tau^{2}-\tau_{m}^{2}<0$ implies that mispricing is relevant for investment. Dots indicate significance. 
OLS Estimates of Investment-q Sensitivity

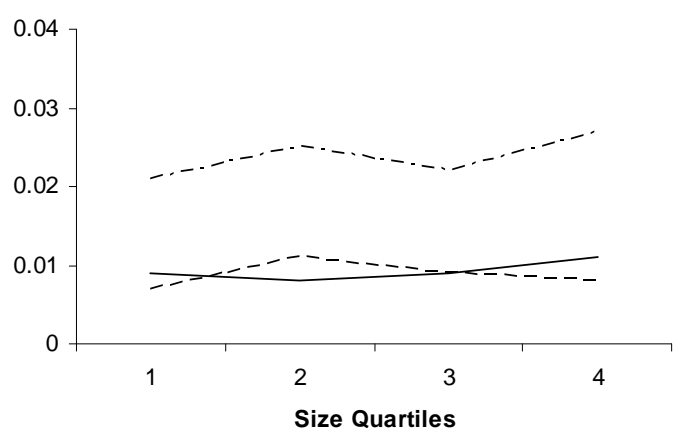

GMM Estimates of Investment- $q$ Sensitivity

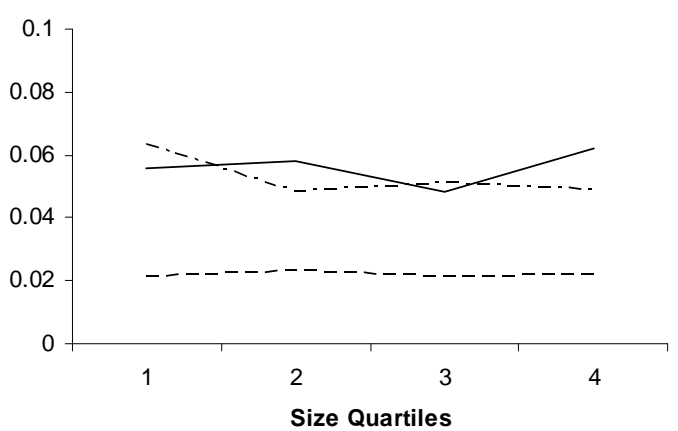

Mispricing Tests

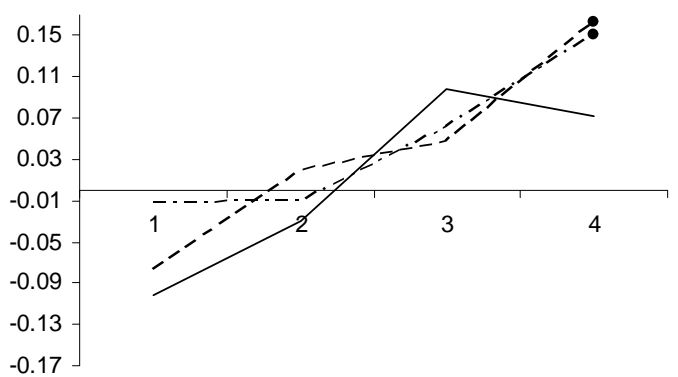

Size Quartiles
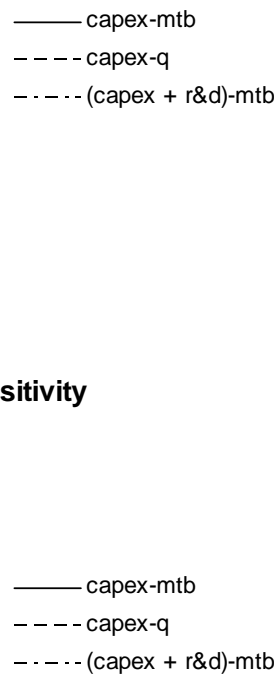

- capex-mtb

-- - capex-q

$-\cdot-\cdot$ (capex + r\&d)-mtb

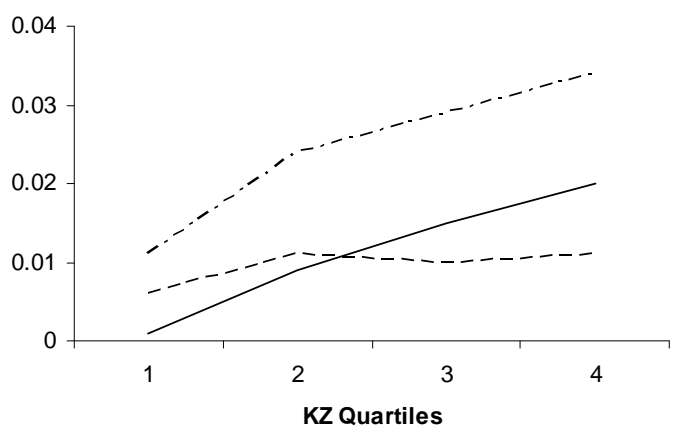

GMM Estimates of Investment- $q$ Sensitivity

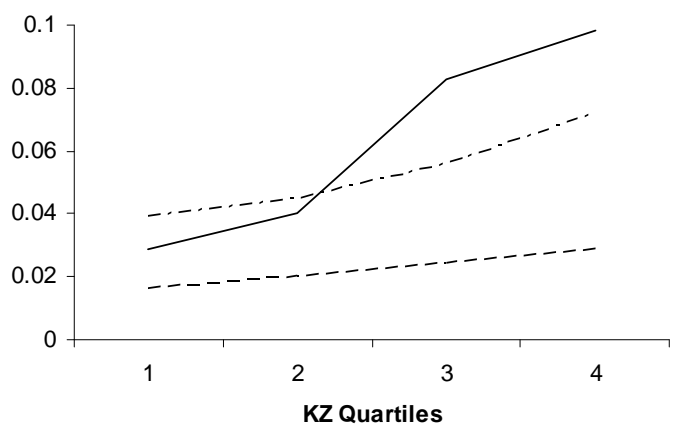

Mispricing Tests

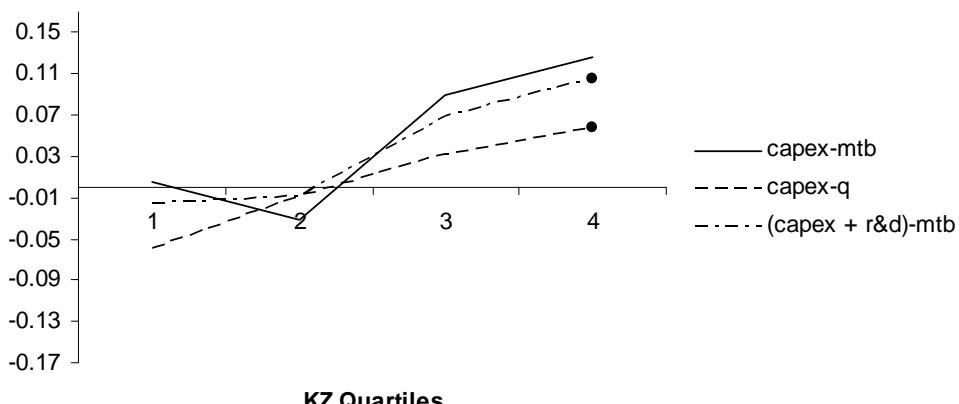

